\title{
Falsificação de Medicamentos e a Lei n. 11.903/09: Aspectos Legais e Principais Implicações
}

\author{
COUNTERFEIT DRUGS AND LAWN. 11.903/09: \\ LEGAL ASPECTS AND IMPACTS
}

\author{
Ellen Nogueira ${ }^{(*)}$ \\ Gonzalo Vecina Neto ${ }^{(* *)}$
}

\section{RESUMO}

Objetiva-se neste trabalho descrever as normas federais que regulam a cadeia farmacêutica e os mecanismos previstos para combate da falsificação, avaliar os medicamentos falsificados no período de 2005 a 2009 e especialmente delinear o escopo da Lei $n$. 11.903/09 e as principais implicações na cadeia mediante pesquisa bibliográfica e aplicação de questionário a associações de indústrias farmacêuticas. Foi observado neste trabalho um aumento no número de lotes de medicamentos falsificados no período de 2005 a 2009 no Brasil. A inclusão do mecanismo de autenticidade (etiqueta de segurança) e de rastreabilidade (código bidimensional) em todas as unidades de medicamentos prevista pela Lei $\mathrm{n}$. 11.903/09 pode reduzir o número de casos de medicamentos falsificados, entretanto, outras medidas devem ser realizadas concomitantemente para o combate do mercado ilegal, tais como a fiscalização contínua e conscientização da população sobre os riscos de medicamentos falsificados. A implantação do novo sistema acarretará em aumento de gastos em todos os atores da cadeia farmacêutica, em especial na indústria farmacêutica, principalmente, se for ratificada a inclusão da etiqueta. Os desafios para implantação do sistema incluem a complexidade do mesmo e o número de

(*) Pós-graduanda em Direito Sanitário, Faculdade de Saúde Pública, Universidade de São Paulo. São Paulo/SP, Brasil. E-mail: <ellennogueira@yahoo.com.br>.

$\left.{ }^{(*}\right)$ Médico. Ex-Diretor Presidente da Agência Nacional de Vigilância Sanitária (ANVISA) no período de 1999 a 2002. Professor Assistente da Faculdade de Saúde Pública, Universidade de São Paulo. São Paulo/SP, Brasil. E-mail: <gvecina@uol.com.br>.

Texto recebido em 17.09.10. Revisado em 09.03.11. Aprovado em 15.03.11. 
atores envolvidos - o país conta com cerca de 3.800 distribuidoras e mais 79.000 de farmácias e drogarias - além dos prazos definidos pela Lei.

\section{Palavras-chave:}

Falsificação de Medicamentos; Lei n. 11.903/09; Rastreabilidade de Medicamentos; Sistema Nacional de Controle de Medicamentos.

\section{ABSTRACT}

The objective of this article is to describe federal regulations that regulate the pharmaceutical chain and existing mechanisms to prevent counterfeiting, to assess the number of counterfeit drugs during the period 2005 to 2009 and especially to describe the scope of Law n. 11.903/09 and major implications for the chain through literature review and a questionnaire completed by pharmaceutical industries' associations. The number of batches of counterfeit drugs increased during the period 2005 to 2009 in Brazil. The inclusion of an authenticity mechanism (security label) and traceability (two-dimensional code) in all drugs' packages stipulated by Law 11.902/09 can reduce the number of cases of counterfeit drugs; however, other measures must be carried out concurrently to prevent the illicit market, such as continuous monitoring and public awareness of the risks of counterfeit medicines. The implementation of the new system will lead to increase costs in the pharmaceutical chain, particularly in the pharmaceutical industry, especially if it is ratified the inclusion of the label. The challenges for implementation of the system include the system complexity and the number of parts involved - the country has about 3,800 distributors and over 79,000 prescription pharmacies and drugstores as well as the deadlines defined by this law.

\section{Keywords:}

Brazilian Law 11.903/09; Brazilian National System of Drug Control; Counterfeit Drug; Drug Traceability.

\section{INTRODUÇÃO}

A questão de falsificação de medicamentos foi abordada pela primeira vez no âmbito mundial na Conferência de Especialistas sobre o Uso Racional 
de Medicamentos, em Nairóbi no Quênia (1985)(1) e entre as recomendações do encontro foi o estudo da viabilidade de criação de um organismo central para coletar dados e informar os governos sobre a natureza e extensão do problema. ${ }^{(2)(3)}$

Como a ausência de uma definição aceita mundialmente poderia dificultar a troca de informações e limitar o conhecimento da extensão do problema, durante o primeiro encontro internacional sobre medicamentos falsificados na Organização Mundial da Saúde (OMS) em Genebra em 1992, com a participação dos Estados-membros, da Interpol, da Federação Internacional da Indústria de Medicamentos (IFPMA), dentre outras instituições, foi acordado que medicamentos falsificados são aqueles rotulados de forma intencional e fraudulenta quanto à origem e/ou identidade, aplicável tanto a produtos genéricos como aos de marca, podendo apresentar ingredientes corretos ou incorretos, sem princípios ativos ou com quantidade insuficiente de princípios ativos ou com embalagem falsificada ${ }^{(4)}$.

Apesar de o termo medicamento irregular ser utilizado como sinônimo de medicamento falsificado pela mídia e não existir uma definição legal para o termo, os medicamentos irregulares podem ser definidos como aqueles que não atendem aos padrões de qualidade exigidos ou não estão de acordo com a legislação vigente e, portanto, englobam além dos medicamentos falsificados, os medicamentos sem registro, adulterados, contrabandeados ou com prazo de validade vencido. No presente artigo, será adotada a definição da OMS para medicamentos falsificados, descrita anteriormente.

O aumento do comércio internacional de medicamentos e as vendas pela internet que facilitam a entrada de produtos falsificados na cadeia levaram a OMS a lançar em 2006 a primeira força-tarefa internacional de combate à falsificação de produtos farmacêuticos (IMPACT), formada pela Interpol, Organização de Propriedade Intelectual, agências e associações de países desenvolvidos e em desenvolvimento de forma a dividir conhecimento, identificar problemas, buscar soluções e coordenar as atividades. Os grupos de trabalho da IMPACT são direcionados às áreas nas quais ações são necessárias, a saber: infraestrutura regulatória e legislativa, implementação regulatória, cumprimento [enforcement], tecnologia e comunicação(5).

Nas Américas, o tema de falsificação foi incluso na II Conferência Pan-Americana da OPAS/OMS em 1999 quando foram criadas a Rede Pan-

(1) WORLD HEALTH ORGANIZATION. General information on counterfeit medicines. Disponível em: <http://www.who.int/medicines/services/counterfeit/overview/en/>. Acesso em: 13 jun. 2010.

(2) WORLD HEALTH ORGANIZATION. Counterfeit medicines. Disponível em: < http://www.who.int/ medicines/services/counterfeit/en/>. Acesso em: 07 mar. 2011.

(3) WORLD HEALTH ORGANIZATION. The rational use of drugs. Report of the Conference

(4) WORLD HEALTH ORGANIZATION. General information on counterfeit medicines. Disponível em: <http://www.who.int/medicines/services/counterfeit/overview/en/>. Acesso em: 13 jun. 2010.

(5) INTERNATIONAL MEDICAL PRODUCTS ANTI-COUNTERFEITING TASKFORCE. FREQUENTLY ASKED QUESTIONS (IMPACT). Disponível em: <http://www.who.int/impact/impact_q-a/en/index.html>. Acesso em: 13 jun. 2010. 
-Americana de Harmonização da Regulamentação Farmacêutica (PANDRHA) e o grupo de combate à falsificação (GT/FAL), coordenado pela ANVISA. Durante o primeiro encontro do grupo (2001), foi introduzida uma pesquisa sobre a situação de medicamentos falsificados nas Américas e Caribe. O GT/ FAL concluiu que vários países não apresentavam definição e mecanismos para prevenção e combate à falsificação e foi elaborada uma proposta de plano de ação conjunta para prevenção e combate à falsificação, aprovado durante a III Conferência Pan-Americana de Harmonização de Regulamentação Farmacêutica (2002). Em 2003, durante o segundo encontro do grupo, foram definidos a missão e objetivos do GT e na terceira reunião foi discutida a proposta de curso regional de capacitação das autoridades sanitárias. Na IV Conferência (2005), foram aprovados os documentos Rota Crítica, com a proposta de desenvolvimento por país de um plano de ação de forma a identificar medicamentos falsificados, o documento Unidade Executora, com a proposta de criação de uma unidade flexível (parte da Autoridade Sanitária) para monitorar e controlar a qualidade e segurança dos medicamentos disponíveis no país, o documento Indicadores, que contém os indicadores para monitorar e avaliar as ações no país, tais como manejo das denúncias e capacidade de resolução de problemas e o documento Programa Educativo, com a proposta de curso para treinamento dos recursos humanos para prevenção e combate à falsificação de medicamentos ${ }^{(6)}$. Na última reunião, realizada em 2006, foi estabelecido um novo plano de trabalho de 2007 e 2008. Foi realizado um piloto da Jornada de Discussão de Ferramentas e Geração de Propostas para Prevenção e Combate da Falsificação de Medicamentos em 2008, sendo definidas ações prioritárias. Solicitado pelo Panamá, o projeto piloto foi realizado na Cidade do Panamá no período de 5 a 8 de agosto de 2008 .

Embora não seja totalmente conhecida a extensão do problema, a OMS estima que a proporção de medicamentos falsificados atinja $1 \%$ em países desenvolvidos com sistemas regulatórios efetivos e controle de mercado e $10 \%$ em países em desenvolvimento, podendo chegar a $20 \%$ nos países da extinta União Soviética e mais de $30 \%$ em algumas partes da América Latina, do Sudeste Asiático e da África Subsaariana (2008) ${ }^{(7)}$.

Em abril de 2010, a OMS emitiu um boletim com um alerta do crescimento do número de medicamentos falsificados e ilegais, com base nos dados de 2009, como os 20 milhões de pílulas, frascos e sachês apreendidos em uma operação, com 5 meses de duração, coordenada pela Interpol na China e em sete países vizinhos do Sudeste Asiático e os 34 milhões de pílulas

(6) WORLD HEALTH ORGANIZATION. Working Group for Prevention and Combat Drug Counterfeiting. Disponível em: $<$ http://new.paho.org/hq/index.php?option=com_content\&task=view\&id=1583\&ltemid= 513\&lang=en>. Acesso em: 26 jun. 2010.

(7) WORLD HEALTH ORGANIZATION. Counterfeit Drugs Kill! Disponível em: <http://www.who.int/ impact/FinalBrochureWHA2008a.pdf>. Acesso em: 12 jun. 2010. 
apreendidas na Europa em apenas 2 meses. Segundo especialistas, os resultados destas operações demonstram que foi atingida apenas a superfície de uma indústria crescente que coloca em risco o mundo inteiro ${ }^{(8)}$. Recentemente, também, foram descobertos vários casos de medicamentos falsificados para tratamento de câncer e doenças cardíacas graves, vendidos pela internet. De acordo com uma pesquisa realizada pelo Pharmaceutical Security Institute (PSI), foram registrados no ano passado no mundo 1.693 incidentes de medicamentos falsificados, representando um aumento de $7 \% .^{\left({ }^{9}\right)}$ No ano de 2009, já havia sido registrado um aumento de $50 \%$ com relação ao ano anterior. Segundo o PSI, apesar de o aumento poder ser atribuído em parte à melhora na coleta de dados, aos esforços para cumprimento das leis e maior consciência da população, esses dados mostram a extensão do problema antes desconhecida e que a atividade criminosa tem aumentado.

A falsificação de medicamentos é uma atividade ilegal muito lucrativa, considerando o baixo custo de produção destes produtos, sem os padrões de qualidade e segurança necessários. Em artigo publicado em 2005 na revista PLoS Medicine, a Food and Drug Administration (FDA), a Agência Regulatória Americana, estimou que as vendas de produtos falsificados passavam de 3,5 bilhões de dólares. Segundo o Dr. Peter Pitts do Centro de Medicamentos de Interesse Público [Center for Medicine in the Public Interest] dos EUA, estima-se que as vendas mundiais de medicamentos falsificados em 2010 atinjam US\$ 75 bilhões, representando um aumento de 92\% comparado com 2005(10).

Os maiores alvos de falsificação são os medicamentos de volume grande de vendas e os de maior valor agregado; segundo a OMS, o maior número de relatos de falsificação envolve antibióticos, antiprotozoários, hormônios e esteroides ${ }^{(11)}$. De acordo com a Interpol, que é um dos membros da força-tarefa no combate à falsificação de medicamentos da OMS (IMPACT), os medicamentos mais pirateados em 21 países, incluindo o Brasil, são os para disfunção erétil, seguido por medicamentos para obesidade ${ }^{(12)}$.

(8) GROWING threat from counterfeit medicines. Bulletin of the World Health Organization, v. 88, p. 247-248, 2010. Disponível em: <http://www.who.int/bulletin/volumes/88/4/10-020410.pdf>. Acesso em: 20 jun. 2010.

(9) INTERNATIONAL FEDERATION OF PHARMACEUTICAL MANUFACTURERS \& ASSOCIATIONS. IFPMA launches Ten Principles on Counterfeit Medicines. 12 maio 2010. Disponível em: <http:// www.ifpma.org/News/NewsReleaseDetail.aspx?nID=13800>. Acesso em: 26 jun. 2010.

(10) BURNS, W. WHO launches taskforce to fight counterfeit drugs. Bulletin of the World Health Organization, v.84, n.9, p. 689-90, 2006. Disponível em: <http://www.who.int/bulletin/volumes/84/9/ news.pdf $>$. Acesso em: 20 jun. 2010.

(11) WORLD HEALTH ORGANIZATION. Frequently Asked Questions (Counterfeit medicine). Disponível em: <http://www.who.int/medicines/services/counterfeit/faqs/en/index.html>. Acesso em: 18 jun. 2009. (12) COURA, K. Dispara a venda ilegal na internet de remédios para emagrecer, ganhar músculos e até abortar. Oito em cada dez desses produtos são falsificados. E alguns deles não passam de farinha. Veja.com. 10 mar. 2010. Disponível em: <http://veja.abril.com.br/100310/perigo-com-p124.shtml>. Acesso em: 13 jun. 2010. 
Como não são conhecidas a (verdadeira) fonte e a identidade dos produtos, que são produzidos por criminosos com fins de obtenção ilegal de dinheiro, não há como assegurar a qualidade de produtos falsificados, podendo levar a falhas terapêuticas e mortes, como ocorreu com vários pacientes que receberam ampolas falsificadas de ferro que continham três vezes a quantidade de ferro do produto original na Argentina no final de 2004 e no Panamá em 2006 onde morreram mais de 100 pacientes que utilizaram xarope para tosse cuja fórmula continha, ao invés do excipiente glicerina, o dietilenoglicol, uma substância altamente tóxica para os rins e sistema nervoso central|(13). Em 2008, 150 pessoas foram internadas em Singapura com hipoglicemia severa após o uso de produtos falsificados para disfunção erétil.(14) Destas, 4 foram a óbito e 7 sofreram danos cerebrais graves, em decorrência de alta dose de glibenclamida presente nos medicamentos.

Além dos efeitos na saúde da população, a falsificação pode também abalar a confiança da população nos sistemas de saúde, nos profissionais de saúde, nos fornecedores, vendedores de medicamentos originais, indústrias farmacêuticase até a credibilidade da Autoridade Sanitária ${ }^{(15)}$.

Segundo a OMS, são vários os fatores que contribuem para a falsificação de medicamentos. A falta de legislação ou leis inadequadas, a falta de controles adequados que deixam os sistemas mais vulneráveis e com baixa capacidade de descobrir e punir os falsificadores, como também a falta de cooperação e troca de informações entre as partes envolvidas, autoridades sanitárias, consumidores, polícia, indústrias e comerciantes. Ademais, a falta de disposição de autoridades sanitárias, não preparadas para reconhecer a existência do problema e de perseguir os falsificadores ou ainda quando não há uma preocupação com a saúde pública comparada a interesses comerciais. Outro fator é o desconhecimento dos riscos de medicamentos falsificados pelos profissionais de saúde e pacientes, mesmo quando estes apresentam ineficácia do tratamento ou reações adversas. Adicionalmente, os custos dos medicamentos verdadeiros, mesmo os genéricos, são muito elevados para os pacientes, facilitando a busca por barganhas no mercado não regulado como feiras e internet. Além disso, muitos intermediários na cadeia aumentam as oportunidades para falsificadores se infiltrarem no sistema regulado de distribuição, assim como conflito de interesses e corrupção dentro da Autoridade Sanitária. Também contribuem para a falsificação a falta de regulamentação para produtos

(13) WORLD HEALTH ORGANIZATION. Counterfeit Drugs Kill! Disponível em: <http://www.who.int/ impact/FinalBrochureWHA2008a.pdf>. Acesso em: 12 jun. 2010.

(14) GROWING threat from counterfeit medicines. Bulletin of the World Health Organization, v. 88, p. 247-248, 2010. Disponível em: <http://www.who.int/bulletin/volumes/88/4/10-020410.pdf>. Acesso em: 20 jun. 2010.

(15) WORLD HEALTH ORGANIZATION. Guidelines for the development of measures to combact counterfeit drugs. Disponível em: <http://whqlibdoc.who.int/hq/1999/WHO_EDM_QSM_99.1.pdf>. Acesso em: 26 jun. 2010. 
destinados exclusivamente à exportação, não produzidos com o mesmo padrão de qualidade dos produzidos para o mercado interno, como também o comércio dentro de zonas de livre comércio com pouco controle e onde se faz necessário reembalar ou rerrotular os produtos.

As ações prioritárias para os países descritas pela OMS (2008) incluem o fortalecimento da legislação de forma que a falsificação de medicamentos seja configurada como crime e a certeza de sua punição na medida das consequências para a saúde e para a credibilidade do sistema nacional de saúde. Além disso, deve-se assegurar que os fabricantes, importadores, exportadores, distribuidores e varejistas atendam aos requisitos necessários para a distribuição segura de medicamentos. Ademais, o combate da falsificação deve incluir a colaboração entre as partes, como o setor de saúde, polícia, consumidores e judiciário. Incluem-se também as estratégias de comunicação de maneira a informar os riscos aos profissionais de saúde, público em geral incluindo divulgação na mídia. Considerando a dimensão internacional do problema, também se faz necessária a cooperação entre os países para combate à falsificação(16)(17).

O presente artigo se insere neste contexto, considerando que a falsificação de medicamentos representa um grave problema de saúde pública, podendo levar à ineficácia terapêutica, resistência a antibióticos, intoxicação, agravamento da doença e, em casos mais extremos, à morte $^{(18)(19)(20)(21)}$.

Em 2009, sob a justificativa de garantir a segurança e eficácia dos medicamentos, foi publicada no Brasil a Lei n. 11.903/09 que prevê o rastreamento dos produtos em toda a cadeia farmacêutica até seu consumo por meio de tecnologia de captura, armazenamento e transmissão eletrônica de $\operatorname{dados}^{(22)}$.

(16) INTERNATIONAL MEDICAL PRODUCTS ANTI-COUNTERFEITING TASKFORCE (IMPACT) Terms of Reference. Disponível em <http://www.who.int/impact/about/IMPACT_ToR.pdf>. Acesso em: 13 jun. 2010. (17) INTERNATIONAL FEDERATION OF PHARMACEUTICAL MANUFACTURERS \& ASSOCIATION. The IFPMA Ten Principles on Counterfeit Medicines. 12 maio 2010. Disponível em: <http://www.ifpma.org/ documents/NR13800/IFPMA_Ten_Principles_on_Counterfeit_Medicines_12May2010.pdf>. Acesso em: 26 jun. 2010.

(18) CRUZ, S. G. Falsificação de remédios e poder de polícia. Rio de Janeiro: América Jurídica, 2001. p.107.

(19) WORLD HEALTH ORGANIZATION. Frequently Asked Questions (Counterfeit medicine). Disponível em: <http://www.who.int/medicines/services/counterfeit/faqs/en/index.html>. Acesso em: 18 jun. 2009. (20) GROWING threat from counterfeit medicines. Bulletin of the World Health Organization, v. 88, p. 247-248, 2010. Disponível em: <http://www.who.int/bulletin/volumes/88/4/10-020410.pdf>. Acesso em: 20 jun. 2010.

(21) SEADI, J. A. Crimes hediondos e a falsificação de medicamentos. Porto Alegre: EDIPUCRS, 2002. p. 74-5.

(22) BRASIL. Projeto de Lei PL n. 6672/2002. Disponível em: <http://www.camara.gov.br/internet/ sileg/Prop_Detalhe.asp?id=50589>. Acesso em: 24 jun. 2010 
Objetiva-se neste trabalho descrever as normas federais que regulam a cadeia farmacêutica e os mecanismos previstos para combate da falsificação, avaliar os medicamentos falsificados no período de 2005 a 2009 e especialmente delinear o escopo da Lei n. 11.903/09 e as principais implicações na cadeia.

\section{LEGISLAÇÃO E PANORAMA DA FALSIFICAÇÃO NO BRASIL}

O primeiro caso de falsificação no Brasil foi registrado em 1877 (água inglesa). Posteriormente, em 1991, foi verificado que de 11 marcas do antibiótico tetraciclina, 9 eram falsificadas ${ }^{(23)}$.

No período de 1997 e 1998, a prática de falsificação se agravou, sendo registrados 172 casos de falsificação pelo Ministério da Saúde. Entre estes, está a falsificação pela máfia de medicamentos do produto Androcur, indicado para o tratamento de câncer de próstata, da empresa Schering do Brasil, levando ao agravamento da doença e a óbito pelo menos 5 pacientes que utilizavam o medicamento(24).

Outro caso extremamente grave foi a falsificação do antibiótico trioxina que ocasionou a morte de uma criança, demonstrando a crueldade e o descaso dos falsificadores ${ }^{(25)}$.

A partir desses casos, foram adotadas várias medidas pelo Governo, inclusive a modificação do Código Penal, passando a enquadrar a falsificação como crime hediondo, sujeita à pena de 10 a 15 anos e multa, com a publicação das Leis ns. 9.677/98 e 9.695/98.

Ademais, foram publicadas Portarias pelo Ministério da Saúde com importante impacto em todos os setores da cadeia e, consequentemente, uma significativa redução no número de falsificações foi observada nos anos posteriores.

Por exemplo, a Portaria n. 802 de outubro de 1998 que instituiu o Sistema de Controle e Fiscalização em toda cadeia dos produtos farmacêuticos, determinando a obrigatoriedade de inclusão em cada unidade produzida do número de registro no Ministério de Saúde, nome do responsável técnico e o respectivo número do Conselho Regional de Farmácia, data de fabricação e validade, número de lote, nome e endereço

(23) E se o medicamento for falso? Disponível em: <http://portal.anvisa.gov.br/wps/wcm/connect/ 66345900406aafbf9b5efb137b78f2dc/terceira_falsificados1.pdf?MOD=AJPERES>. Acesso em: 19 jun. 2010.

(24) O REINCIDENTE. Revista Veja. 22 jul. 1998. Disponível em: <http://veja.abril.com.br/220798/ p_045a.html>. Acesso em: 19 jun. 2010.

(25) CRUZ, S. G. Falsificação de remédios e poder de polícia. Rio de Janeiro: América Jurídica, 2001. p. 99-101. 
do serviço de atendimento ao consumidor, código de barras EAN e tinta reativa, sob a qual deviam constar a palavra qualidade e a logomarca da empresa, lacre ou selo de segurança de rompimento irrecuperável e detectável. Outro ponto importante foi a exigência da inclusão do número do lote nas notas fiscais de venda. Para as distribuidoras passou também a exigir a Autorização de Funcionamento e Boas Práticas de Distribuição, presença de Farmacêutico Responsável, além do dever de somente distribuir medicamentos legalmente registrados no país, abastecer-se somente em empresas titulares de registro de produtos, fornecer produtos a estabelecimentos licenciados que vão dispensar produtos farmacêuticos e notificar a autoridade sanitária competente, em caráter de urgência, quaisquer suspeitas de alteração, adulteração, fraude ou falsificação dos produtos com a indicação do número do lote e efetuar as transações comerciais por meio de nota fiscal que conterá obrigatoriamente o número dos lotes dos produtos farmacêuticos.

Ademais, passou a ser obrigatória a Autorização de Funcionamento para exercer a atividade de transporte, conforme disposto na Portaria $n$. 1.052/98.

A própria criação da ANVS (atual ANVISA) em 1999 representou um importante avanço para o setor farmacêutico. Após a criação da Agência, apenas sete falsificações foram confirmadas no período entre 1999 e $2003^{(26)}$.

A Comissão Parlamentar de Inquérito (CPI) de Medicamentos, realizada no período de novembro de 1999 a maio de 2000, levantou questões importantes sobre a precariedade no setor farmacêutico brasileiro e a falta de acesso pelas classes mais baixas da população. No relatório, também foram emitidas recomendações para que essas deficiências fossem sanadas, por exemplo, a elaboração de um plano de fortalecimento da ANVISA, maior transferência de recursos aos estados e municípios de forma a aumentar o poder fiscalizatório do sistema, elaboração de política dirigida às farmácias e drogarias, inclusive fiscalização constante e a proibição de venda eletrônica de medicamentos ${ }^{(27)}$.

A RDC n. 320 publicada em 2002 ratifica a obrigatoriedade de inclusão do número de lote do medicamento nas notas fiscais das distribuidoras, devendo ser idêntico ao que consta nas embalagens dos medicamentos, permitindo maior monitoramento do mercado e possibilitando a comprovação da procedência dos produtos.

Em março de 2008, a ANVISA publicou a Consulta Pública 08 que define os requisitos mínimos para os mecanismos de rastreabilidade e

(26) FÓRUM discute estratégias de combate à falsificação de medicamentos. Revista de Saúde Pública, São Paulo, v. 38, n. 5, p. 748-749, 2004. Disponível em: <http://www.scielo.br/pdf/rsp/ v38n5/21770.pdf>. Acesso em: 26 jun. 2010.

(27) SEADI, J. A. Crimes hediondos e a falsificação de medicamentos. Porto Alegre: EDIPUCRS, 2002. p. 89-90. 
autenticidade de medicamentos. Foram enviadas várias contribuições com sugestões de soluções tecnológicas e de janeiro a julho de 2009 foi realizado um projeto piloto por 7 empresas organizado pelo Instituto Brasileiro de Ética Concorrencial (Etco) ${ }^{(28)}$. A ANVISA também assinou em 2008 um termo de cooperação com o Conselho Nacional de Pirataria (CNCP) do Ministério da Justiça. De forma a intensificar as ações de repressão da falsificação de medicamentos, estava previsto neste convênio a assessoria técnica nas ações da Polícia Federal(29)(30).

Em 2009, o presidente Luís Inácio Lula da Silva sanciona a Lei $n$. 11.903 que cria o Sistema Nacional de Controle de Medicamentos, mediante o qual todo e qualquer medicamento produzido, dispensado ou vendido no país será controlado por um sistema de identificação única dos produtos, com emprego de uma tecnologia de captura, armazenamento e transmissão eletrônica dos dados.

A regulamentação da Lei n. 11.903/09 foi feita pela RDC n. 59/09, a qual definiu os mecanismos para rastreamento de medicamentos, por meio de tecnologia de captura, armazenamento e transmissão eletrônica de dados.

A venda de medicamentos por meio remoto (internet, telefone e fac-símile) foi regulamentada pela ANVISA pela RDC n. 44/09, restringindo a venda de produtos sob prescrição médica a farmácias e drogarias abertas ao público com farmacêutico responsável durante todo o horário de funcionamento e vedando a comercialização de medicamentos sujeitos a controle especial (art. 52, § $2^{\circ}$ ).

No Quadro 1, são descritas as principais normas federais que regulam a cadeia de produtos farmacêuticos, formada por importadores e fabricantes de insumos farmacêuticos e medicamentos, distribuidores, transportadoras, farmácias e drogarias.

(28) INSTITUTO BRASILEIRO DE ÉTICA CONCORRENCIAL. SISTEMA ELETRÔNICO DE RASTREAMENTO E AUTENTICIDADE DE MEDICAMENTOS. Etco. Disponível em: <http:// www.etco.org.br/user_file/etco-medicamentos-out2009.pdf>. Acesso em: 23 jun. 2010.

(29) COMBATE à Pirataria. Parcerias. Anvisa. Disponível em: <http://portal.mj.gov.br/data/Pages/ MJF981C78FITEMID1FEF62A7A51144B8990B9F29977F666APTBRIE.htm>. Acesso em: 20 jun. 2010. (30) ANVISA e Ministério da Justiça no combate à pirataria. 4 dez. 2008. Disponível em: <http:// portal.anvisa.gov.br/wps/portal/anvisa/busca/lut/p/c5/04_SB8K8xLLM9MSSzPy8xBz9CP0os3jv QA9PdwMDI0v_EAsXA0-TkCAPS29nfzdDQ6B8pFm8s7ujh4m5j4GBgZmTs4Gnu6mfmWmgv4GBvxEB3 eEg-_DrB8kb4ACOBvp-Hvm5qfqR-IHmOO3xMNKPzEINTOyu1C_IjTDIMgIVBABMM9TI/dI3/d3/ LolJSkIna2shLOICakFBTXIBQkVSQ0IBISEvWUZOQzFOS18yN3chLzdfS1FISUcwMDI5T1Q4RDBJNF RSSDILQ09GSDI!/?WCM_GLOBAL_CONTEXT=/wps/wcm/connect/Anvisa/Anvisa/Sala+de+Imprensa/ Noticias/Anvisa+e+Ministerio+da+Justica+no+combate+a+pirataria>. Acesso em: 20 jun. 2010. 


\section{Quadro 1 - Principais normas federais publicadas para regulação da Cadeia Farmacêutica}

\begin{tabular}{|c|c|c|c|c|}
\hline Ano & Norma & Ementa & Aplica-se a & Situação \\
\hline 1969 & $\begin{array}{l}\text { Decreto-Lei } 785 \text {, de } \\
25.08 .69\end{array}$ & $\begin{array}{l}\text { Dispõe sobre infrações às normas } \\
\text { relativas à saúde e respectivas } \\
\text { penalidades. }\end{array}$ & $\begin{array}{l}\text { - Fabricantes - } \\
\text { Distribuidoras - } \\
\text { Importadoras - } \\
\text { Farmácias e Drogarias }\end{array}$ & $\begin{array}{l}\text { Revogada (pela } \\
\text { Lei } 6.437 / 77 \text { ) }\end{array}$ \\
\hline $1973 / 1974$ & $\begin{array}{l}\text { Lei } 5.991 \text {, de } 17.12 .73 \text { e } \\
\text { Decreto Regulamentador } \\
74.190 \text {, de } 10.06 .74\end{array}$ & $\begin{array}{l}\text { Dispõe sobre o controle sanitário do } \\
\text { comércio de drogas, medicamentos, } \\
\text { insumos farmacêuticos e correlatos, } \\
\text { e dá outras providências. }\end{array}$ & $\begin{array}{l}\text { - Distribuidoras - } \\
\text { Importadoras - } \\
\text { Farmácias e Drogarias }\end{array}$ & Vigente \\
\hline $1976 / 1977$ & $\begin{array}{l}\text { Lei } 6.360 \text {, de } 23.09 .76 \text { e } \\
\text { Decreto Regulamentador } \\
79.094 \text {, de } 05.01 .77\end{array}$ & $\begin{array}{l}\text { Dispõe sobre a Vigilância Sanitá- } \\
\text { ria a que ficam sujeitos os medica- } \\
\text { mentos, as drogas, os insumos } \\
\text { farmacêuticos e correlatos, cosmé- } \\
\text { ticos, saneantes e outros produ- } \\
\text { tos, e dá outras providências. }\end{array}$ & $\begin{array}{l}\text { - Fabricantes - } \\
\text { Distribuidoras - } \\
\text { Importadoras }\end{array}$ & Vigente \\
\hline 1977 & Lei 6.437 de 20.08 .77 & $\begin{array}{l}\text { Configura infrações à legislação } \\
\text { sanitária federal, estabelece as } \\
\text { sanções respectivas, e dá outras } \\
\text { providências. }\end{array}$ & $\begin{array}{l}\text { - Fabricantes - } \\
\text { Distribuidoras - } \\
\text { Importadoras - } \\
\text { Transportadoras - } \\
\text { Farmácias e Drogarias }\end{array}$ & Vigente \\
\hline 1990 & Lei 8.072 , de 25.07 .90 & $\begin{array}{l}\text { Dispõe sobre os crimes hedion- } \\
\text { dos, nos termos do art. } 5^{\circ} \text {, inciso } \\
\text { XLIII, da Constituição Federal, e } \\
\text { determina outras providências. }\end{array}$ & $\begin{array}{l}\text { - Fabricantes - } \\
\text { Distribuidoras - } \\
\text { Importadoras - } \\
\text { Transportadoras - } \\
\text { Farmácias e Drogarias }\end{array}$ & Vigente \\
\hline 1990 & Lei 8.078 , de 11.09 .90 & $\begin{array}{l}\text { Dispõe sobre a proteção do consu- } \\
\text { midor e dá outras providências. }\end{array}$ & $\begin{array}{l}\text { - Fabricantes - } \\
\text { Distribuidoras - } \\
\text { Importadoras - } \\
\text { Transportadoras - } \\
\text { Farmácias e Drogarias }\end{array}$ & Vigente \\
\hline 1990 & Lei 8.137 , de 23.12 .90 & $\begin{array}{l}\text { Define crimes contra a ordem tribu- } \\
\text { tária, econômica e contra as rela- } \\
\text { ções de consumo, e dá outras pro- } \\
\text { vidências. }\end{array}$ & $\begin{array}{l}\text { - Fabricantes - } \\
\text { Distribuidoras - } \\
\text { Importadoras - } \\
\text { Transportadoras - } \\
\text { Farmácias e Drogarias }\end{array}$ & Vigente \\
\hline 1994 & $\begin{array}{l}\text { Instrução Normativa 1, de } \\
30.09 .94\end{array}$ & $\begin{array}{l}\text { Estabelece os documentos neces- } \\
\text { sários para Processos de Peti- } \\
\text { ções, junto à Secretaria de Vigi- } \\
\text { lância Sanitária. }\end{array}$ & - Fabricantes & Alterada \\
\hline 1995 & $\begin{array}{l}\text { Portaria SVS/MS 16, de } \\
06.03 .95\end{array}$ & $\begin{array}{l}\text { Determina a todos os estabeleci- } \\
\text { mentos produtores de medicamen- } \\
\text { tos, o cumprimento das diretrizes } \\
\text { estabelecidas pelo "Guia de Boas } \\
\text { Práticas de Fabricação para indús- } \\
\text { trias farmacêuticas" aprovado na } \\
28^{a} \text { Assembleia Mundial de Saú- } \\
\text { de em maio de } 1975 \text {. }\end{array}$ & - Fabricantes & $\begin{array}{c}\text { Revogada (pela } \\
\text { RDC 134/01) }\end{array}$ \\
\hline 1997 & Portaria 110 , de 10.03 .97 & $\begin{array}{l}\text { Institui roteiro para texto de bula } \\
\text { de medicamentos }\end{array}$ & $\begin{array}{l}\text { - Fabricantes - } \\
\text { Importadoras }\end{array}$ & $\begin{array}{l}\text { Revogada (pela } \\
\text { RDC 47/09) }\end{array}$ \\
\hline 1997 & Portaria 450 , de 19.09 .97 & $\begin{array}{l}\text { Aprova o Regulamento Técnico so- } \\
\text { bre Regime de Inspeções aplicável } \\
\text { à realização de inspeções no país } \\
\text { ou entre países no âmbito do MER- } \\
\text { COSUL, relacionadas com Produ- } \\
\text { tos para a Saúde - Produtos Far- } \\
\text { macêuticos e Farmoquímicos, San- } \\
\text { gue e Hemoderivados, Cosméticos, } \\
\text { Saneantes e Correlatos. }\end{array}$ & - Fabricantes & Vigente \\
\hline 1997 & Portaria 500 , de 09.10 .97 & $\begin{array}{l}\text { Aprova o Regulamento técnico de } \\
\text { Soluções Parenterais de Grande } \\
\text { Volume - SPGV. }\end{array}$ & $\begin{array}{l}\text { - Fabricantes - } \\
\text { Distribuidoras - } \\
\text { Importadoras - } \\
\text { Transportadoras }\end{array}$ & $\begin{array}{l}\text { Revogada (pelas } \\
\text { RDC 210/03 e } \\
\text { RDC 17/10) }\end{array}$ \\
\hline 1998 & Portaria 2.814 de 29.05 .98 & $\begin{array}{l}\text { Estabelece procedimentos a se- } \\
\text { rem observados pelas empresas } \\
\text { produtoras, importadoras, distribui- } \\
\text { doras e do comércio farmacêutico. }\end{array}$ & $\begin{array}{l}\text { - Fabricantes - } \\
\text { Distribuidoras - } \\
\text { Importadoras - } \\
\text { Farmácias e Drogarias }\end{array}$ & Vigente \\
\hline
\end{tabular}




\begin{tabular}{|c|c|c|c|c|}
\hline Ano & Norma & Ementa & Aplica-se a & Situação \\
\hline 1998 & Lei 9.677 , de 02.07 .98 & $\begin{array}{l}\text { Altera dispositivos do Capítulo III } \\
\text { do Título VIII do Código Penal, in- } \\
\text { cluindo na classificação dos deli- } \\
\text { tos considerados hediondos cri- } \\
\text { mes contra a saúde pública, e dá } \\
\text { outras providências. }\end{array}$ & $\begin{array}{l}\text { - Fabricantes - } \\
\text { Distribuidoras - } \\
\text { Importadoras - } \\
\text { Transportadoras - } \\
\text { Farmácias e Drogarias }\end{array}$ & Vigente \\
\hline 1998 & Lei 9.695 , de 20.08 .98 & $\begin{array}{l}\text { Acrescenta incisos ao art. } 1^{\circ} \text { da } \\
\text { Lei no } 8.072 \text {, de } 25.07 .90 \text {, que dis- } \\
\text { põe sobre os crimes hediondos, e } \\
\text { altera os artigos } 2^{\circ}, 5^{\circ} \text { e } 10 \text { da Lei } \\
\text { n. } 6.437 \text {, de } 20 \text { de agosto de } 1977 \text {, } \\
\text { e dá outras providências. }\end{array}$ & $\begin{array}{l}\text { - Fabricantes - } \\
\text { Distribuidoras - } \\
\text { Importadoras - } \\
\text { Transportadoras - } \\
\text { Farmácias e Drogarias }\end{array}$ & Vigente \\
\hline 1998 & Portaria 802 , de 08.10 .98 & $\begin{array}{l}\text { Institui o Sistema de Controle e } \\
\text { Fiscalização em toda a cadeia dos } \\
\text { produtos farmacêuticos. }\end{array}$ & $\begin{array}{l}\text { - Fabricantes - } \\
\text { Distribuidoras - } \\
\text { Importadoras - } \\
\text { Transportadoras - } \\
\text { Farmácias e Drogarias }\end{array}$ & Vigente \\
\hline 1998 & Portaria 1.052 , de 29.12 .98 & $\begin{array}{l}\text { Aprova a relação de documentos } \\
\text { necessários para habilitar a em- } \\
\text { presa a exercer a atividade de trans- } \\
\text { porte de produtos farmacêuticos e } \\
\text { farmoquímicos, sujeitos à Vigilân- } \\
\text { cia Sanitária. }\end{array}$ & - Transportadoras & Vigente \\
\hline 1999 & Portaria 185 , de 08.03 .99 & $\begin{array}{l}\text { A importação de produtos farma- } \\
\text { cêuticos sujeitos ao Regime de } \\
\text { Vigilância Sanitária somente po- } \\
\text { derá ser efetuada por empresa le- } \\
\text { galmente autorizada como impor- } \\
\text { tadora pela Secretaria de Vigilân- } \\
\text { cia Sanitária/Ministério da Saúde }\end{array}$ & - Importadoras & Vigente \\
\hline 1999 & $\begin{array}{l}\text { Resolução } 327 \text {, de } \\
22.07 .99\end{array}$ & $\begin{array}{l}\text { Institui o Roteiro sucinto de Inspe- } \\
\text { ção de indústrias farmacêuticas para } \\
\text { fins de Autorização de Funciona- } \\
\text { mento de empresa. }\end{array}$ & - Fabricantes & Vigente \\
\hline 1999 & $\begin{array}{l}\text { Resolução } 328 \text {, de } \\
22.07 .99\end{array}$ & $\begin{array}{l}\text { Institui Regulamento Técnico so- } \\
\text { bre as Boas Práticas de Dispensa- } \\
\text { ção de medicamentos em farmáci- } \\
\text { as e drogarias. }\end{array}$ & $\begin{array}{l}\text { - Farmácias e } \\
\text { Drogarias }\end{array}$ & $\begin{array}{l}\text { Revogada (pela } \\
\text { RDC 44/09) }\end{array}$ \\
\hline 1999 & $\begin{array}{l}\text { Resolução } 329 \text {, de } \\
22.07 .99\end{array}$ & $\begin{array}{l}\text { Institui o Roteiro de Inspeção para } \\
\text { transportadoras de medicamentos, } \\
\text { drogas e insumos farmacêuticos. }\end{array}$ & - Transportadoras & Vigente \\
\hline 1999 & $\begin{array}{l}\text { Resolução } 460 \text {, de } \\
14.09 .99\end{array}$ & $\begin{array}{l}\text { Institui e aprova o "Certificado de } \\
\text { Boas Práticas de Fabricação". }\end{array}$ & - Fabricantes & Vigente \\
\hline 1999 & $\begin{array}{l}\text { Resolução RDC 25, de } \\
09.12 .99\end{array}$ & $\begin{array}{l}\text { Aprova o Regulamento Técnico - } \\
\text { Regime de Inspeções aplicável à } \\
\text { realização de inspeções em esta- } \\
\text { belecimentos produtores de medi- } \\
\text { camentos, instalados em países } \\
\text { fora do âmbito do MERCOSUL. }\end{array}$ & - Fabricantes & Alterada \\
\hline 2000 & $\begin{array}{l}\text { Resolução RDC 33, de } \\
\text { 19.04.00 }\end{array}$ & $\begin{array}{l}\text { Aprova o Regulamento Técnico } \\
\text { sobre Boas Práticas de Manipula- } \\
\text { ção de Medicamentos em farmácias } \\
\text { e seus Anexos. }\end{array}$ & $\begin{array}{l}\text { - Farmácias e } \\
\text { Drogarias }\end{array}$ & $\begin{array}{l}\text { Revogada (pela } \\
\text { RDC 67/07) }\end{array}$ \\
\hline 2001 & $\begin{array}{l}\text { Resolução RDC 134, de } \\
\text { 13.07.01 }\end{array}$ & $\begin{array}{l}\text { Determina a todos os estabeleci- } \\
\text { mentos fabricantes de medicamen- } \\
\text { tos, o cumprimento das diretrizes } \\
\text { estabelecidas no Regulamento } \\
\text { Técnico das Boas Práticas para a } \\
\text { Fabricação de Medicamentos. }\end{array}$ & - Fabricantes & $\begin{array}{l}\text { Revogada (pela } \\
\text { RDC 210/03) }\end{array}$ \\
\hline 2001 & $\begin{array}{l}\text { Resolução RDC 238, de } \\
27.12 .01\end{array}$ & $\begin{array}{l}\text { Fornece critérios relativos à Auto- } \\
\text { rização, Renovação, Cancelamen- } \\
\text { to e Alteração da Autorização de } \\
\text { Funcionamento dos estabeleci- } \\
\text { mentos de dispensação de medi- } \\
\text { camentos: farmácias e drogarias. }\end{array}$ & $\begin{array}{l}\text { - Farmácias e } \\
\text { Drogarias }\end{array}$ & Revogada \\
\hline 2002 & $\begin{array}{l}\text { Resolução } 320 \text {, de } \\
22.11 .02\end{array}$ & $\begin{array}{l}\text { Dispõe sobre deveres das empre- } \\
\text { sas distribuidoras de produtos far- } \\
\text { macêuticos. }\end{array}$ & - Distribuidoras & Vigente \\
\hline
\end{tabular}




\begin{tabular}{|c|c|c|c|c|}
\hline Ano & Norma & Ementa & Aplica-se a & Situação \\
\hline 2002 & $\begin{array}{l}\text { Resolução RDC 01, de } \\
06.12 .02\end{array}$ & $\begin{array}{l}\text { Aprova o Regulamento Técnico } \\
\text { para fins de Vigilância Sanitária } \\
\text { de mercadorias importadas. }\end{array}$ & - Importadoras & $\begin{array}{l}\text { Revogada (pela } \\
\text { RDC 350/05) }\end{array}$ \\
\hline 2003 & $\begin{array}{l}\text { Resolução RDC 140, de } \\
29.05 .03\end{array}$ & $\begin{array}{l}\text { Define a forma e o conteúdo das } \\
\text { bulas de todos os medicamentos } \\
\text { registrados. }\end{array}$ & $\begin{array}{l}\text { - Fabricantes - } \\
\text { Importadoras }\end{array}$ & $\begin{array}{l}\text { Revogada (pela } \\
\text { RDC } 47 / 09 \text { ) }\end{array}$ \\
\hline 2003 & $\begin{array}{l}\text { Resolução RDC 210, de } \\
04.08 .03\end{array}$ & $\begin{array}{l}\text { Determina a todos os estabeleci- } \\
\text { mentos fabricantes de medicamen- } \\
\text { tos, o cumprimento das diretrizes } \\
\text { estabelecidas no Regulamento } \\
\text { Técnico das Boas Práticas para a } \\
\text { Fabricação de Medicamentos. }\end{array}$ & - Fabricantes & $\begin{array}{l}\text { Revogada (pela } \\
\text { RDC 17/10) }\end{array}$ \\
\hline 2003 & $\begin{array}{l}\text { Resolução RDC } 333 \text {, de } \\
\text { 19.11.03 }\end{array}$ & $\begin{array}{l}\text { Dispõe sobre rotulagem de medica- } \\
\text { mentos e dá outras providências. }\end{array}$ & $\begin{array}{l}\text { - Fabricantes - } \\
\text { Importadoras }\end{array}$ & $\begin{array}{l}\text { Parcialmente } \\
\text { revogada (pela } \\
\text { RDC } 71 / 09 \text { ) }\end{array}$ \\
\hline 2005 & $\begin{array}{l}\text { Resolução RDC 249, de } \\
\text { 13.09.05 }\end{array}$ & $\begin{array}{l}\text { Determina a todos os estabelecimen- } \\
\text { tos fabricantes de produtos interme- } \\
\text { diários e de insumos farmacêuticos } \\
\text { ativos, o cumprimento das diretrizes } \\
\text { estabelecidas no Regulamento téc- } \\
\text { nico das boas práticas de fabricação } \\
\text { de produtos intermediários e insu- } \\
\text { mos farmacêuticos ativos. }\end{array}$ & $\begin{array}{l}\text { - Fabricantes } \\
\text { (insumos } \\
\text { farmacêuticos ativos) }\end{array}$ & Vigente \\
\hline 2005 & $\begin{array}{l}\text { Resolução RDC 350, de } \\
28.12 .05\end{array}$ & $\begin{array}{l}\text { Dispõe sobre o regulamento técni- } \\
\text { co de Vigilância Sanitária de mer- } \\
\text { cadorias importadas. }\end{array}$ & - Importadoras & $\begin{array}{l}\text { Revogada (pela } \\
\text { RDC } 81 / 08 \text { ) }\end{array}$ \\
\hline 2007 & $\begin{array}{l}\text { Resolução RDC } 27 \text {, de } \\
30.03 .07\end{array}$ & $\begin{array}{l}\text { Dispõe sobre o Sistema Nacional } \\
\text { de Gerenciamento de Produtos } \\
\text { Controlados - SNGPC e estabe- } \\
\text { lece a implantação do módulo para } \\
\text { drogarias e farmácias e dá outras } \\
\text { providências. }\end{array}$ & $\begin{array}{l}\text { - Farmácias e } \\
\text { Drogarias }\end{array}$ & Vigente \\
\hline 2008 & $\begin{array}{l}\text { Resolução RDC } 81 \text {, de } \\
05.11 .08\end{array}$ & $\begin{array}{l}\text { Dispõe sobre o Regulamento Técni- } \\
\text { co de Bens e Produtos Importados } \\
\text { para fins de Vigilância Sanitária. }\end{array}$ & - Importadoras & Vigente \\
\hline 2009 & Lei 11.903 , de 14.01 .09 & $\begin{array}{l}\text { Dispõe sobre o rastreamento da } \\
\text { produção e do consumo de medi- } \\
\text { camentos por meio de tecnologia } \\
\text { de captura, armazenamento e trans- } \\
\text { missão eletrônica de dados. }\end{array}$ & $\begin{array}{l}\text { - Fabricantes - } \\
\text { Importadoras - } \\
\text { Distribuidoras - } \\
\text { Farmácias e Drogarias }\end{array}$ & Vigente \\
\hline 2009 & $\begin{array}{l}\text { Resolução RDC 44, de } \\
17.08 .09\end{array}$ & $\begin{array}{l}\text { Dispõe sobre Boas Práticas Farma- } \\
\text { cêuticas para o controle sanitário } \\
\text { do funcionamento, da dispensação } \\
\text { e da comercialização de produtos e } \\
\text { da prestação de serviços farmacêu- } \\
\text { ticos em farmácias e drogarias e dá } \\
\text { outras providências. }\end{array}$ & $\begin{array}{l}\text { - Farmácias e } \\
\text { Drogarias }\end{array}$ & Vigente \\
\hline 2009 & $\begin{array}{l}\text { Resolução RDC } 47 \text {, de } \\
08.09 .09\end{array}$ & $\begin{array}{l}\text { Determina o aprimoramento da for- } \\
\text { ma e o conteúdo das bulas de to- } \\
\text { dos os medicamentos registrados } \\
\text { e notificados, comercializados no } \\
\text { Brasil, visando à garantia de aces- } \\
\text { so à informação segura e adequa- } \\
\text { da em prol do uso racional de me- } \\
\text { dicamentos. }\end{array}$ & $\begin{array}{l}\text { - Fabricantes - } \\
\text { Importadores }\end{array}$ & Vigente \\
\hline 2009 & $\begin{array}{l}\text { Resolução-RDC } 57 \text {, de } \\
\text { 17.11.09 }\end{array}$ & $\begin{array}{l}\text { Aprova o Regulamento Técnico } \\
\text { para registro de Insumos Farma- } \\
\text { cêuticos Ativos (IFA) no Brasil. }\end{array}$ & $\begin{array}{l}\text { - Fabricantes } \\
\text { (insumos) - } \\
\text { Importadores (insumos) }\end{array}$ & Vigente \\
\hline 2009 & $\begin{array}{l}\text { Instrução Normativa } 15, \mathrm{de} \\
\text { 17.11.09 }\end{array}$ & $\begin{array}{l}\text { Aprova cronograma e as prioriza- } \\
\text { ções para a primeira etapa da im- } \\
\text { plantação do registro de insumos } \\
\text { farmacêuticos ativos (IFA), nos } \\
\text { termos da Resolução RDC } 57 \text {, de } \\
17.11 .09 \text {. }\end{array}$ & $\begin{array}{l}\text { - Fabricantes } \\
\text { (insumos) - } \\
\text { Importadores (insumos) }\end{array}$ & Vigente \\
\hline 2009 & $\begin{array}{l}\text { Resolução RDC } 59 \text {, de } \\
\text { 24.11.09 }\end{array}$ & $\begin{array}{l}\text { Institui o Sistema de rastreamento } \\
\text { de medicamentos em toda a ca- } \\
\text { deia dos produtos farmacêuticos, } \\
\text { da produção e do consumo de me- } \\
\text { dicamentos por meio de tecnolo- }\end{array}$ & $\begin{array}{l}\text { - Fabricantes - } \\
\text { Importadoras - } \\
\text { Distribuidoras - } \\
\text { Farmácias e Drogarias }\end{array}$ & Vigente \\
\hline
\end{tabular}




\begin{tabular}{|c|c|c|c|c|}
\hline Ano & Norma & Ementa & Aplica-se a & Situação \\
\hline & & $\begin{array}{l}\text { gia de captura, armazenamento e } \\
\text { transmissão eletrônica de dados, } \\
\text { como parte integrante do Sistema } \\
\text { Nacional de Controle de Medica- } \\
\text { mentos. }\end{array}$ & & \\
\hline 2009 & $\begin{array}{l}\text { Resolução RDC } 71 \text {, de } \\
22.12 .09\end{array}$ & $\begin{array}{l}\text { Determina o aprimoramento da for- } \\
\text { ma e o conteúdo dos rótulos de to- } \\
\text { dos os medicamentos registrados } \\
\text { e comercializados no Brasil, visan- } \\
\text { do garantir o acesso à informação } \\
\text { segura e adequada em prol do uso } \\
\text { racional de medicamentos. }\end{array}$ & $\begin{array}{l}\text { - Fabricantes - } \\
\text { Importadoras }\end{array}$ & Vigente \\
\hline 2010 & $\begin{array}{l}\text { Instrução Normativa 01, de } \\
\text { 13.01.10 }\end{array}$ & $\begin{array}{l}\text { Regulamenta a Resolução RDC n. } \\
59 \text {, de } 24 \text { de novembro de } 2009 \text {, que } \\
\text { dispõe sobre a implantação do Sis- } \\
\text { tema Nacional de Controle de Me- } \\
\text { dicamentos, com vistas ao regra- } \\
\text { mento da produção e o controle da } \\
\text { distribuição das etiquetas de segu- } \\
\text { rança para o Sistema de Rastrea- } \\
\text { mento de Medicamentos e dá ou- } \\
\text { tras providências. }\end{array}$ & $\begin{array}{l}\text { - Fabricantes - } \\
\text { Importadoras - } \\
\text { Distribuidoras - } \\
\text { Farmácias e Drogarias }\end{array}$ & $\begin{array}{l}\text { Revogada (pela } \\
\text { IN 11/10) }\end{array}$ \\
\hline 2010 & $\begin{array}{l}\text { Resolução RDC 17, de } \\
16.04 .10\end{array}$ & $\begin{array}{l}\text { Requisitos mínimos a serem segui- } \\
\text { dos na fabricação de medicamen- } \\
\text { tos para padronizar a verificação do } \\
\text { cumprimento das Boas Práticas de } \\
\text { Fabricação de Medicamentos (BPF) } \\
\text { de uso humano durante as inspe- } \\
\text { ções sanitárias. }\end{array}$ & - Fabricantes & Vigente \\
\hline 2010 & $\begin{array}{l}\text { Instrução Normativa 08, de } \\
\text { 15.06.10 }\end{array}$ & $\begin{array}{l}\text { Dá nova redação ao caput e revoga } \\
\text { os } \S \S 1^{\circ}, 2^{\circ}, 3^{\circ} \text { e } 4^{\circ} \text { do art. } 9^{\circ} \text { da } \\
\text { Instrução Normativa n. } 1 \text {, de } 13 \text { de } \\
\text { janeiro de } 2010\end{array}$ & $\begin{array}{l}\text { - Fabricantes - } \\
\text { Importadoras - } \\
\text { Distribuidoras - } \\
\text { Farmácias e Drogarias }\end{array}$ & $\begin{array}{l}\text { Revogada (pela } \\
\text { IN 11/10) }\end{array}$ \\
\hline 2010 & $\begin{array}{l}\text { Resolução RDC 29, de } \\
\text { 10.08.10 }\end{array}$ & $\begin{array}{l}\text { Dispõe sobre certificação de Boas } \\
\text { Práticas de Fabricação para fabri- } \\
\text { cantes internacionais de insumos } \\
\text { farmacêuticos ativos. }\end{array}$ & $\begin{array}{l}\text { - Fabricantes } \\
\text { (insumos } \\
\text { farmacêuticos ativos) }\end{array}$ & \\
\hline 2010 & $\begin{array}{l}\text { Instrução Normativa } 11 \text {, de } \\
29.10 .10\end{array}$ & $\begin{array}{l}\text { Dispõe sobre a tecnologia, a produ- } \\
\text { ção, o fornecimento e o controle da } \\
\text { distribuição das etiquetas autoade- } \\
\text { sivas de segurança para o Sistema } \\
\text { de Rastreamento de Medicamentos } \\
\text { e dá outras providências. }\end{array}$ & $\begin{array}{l}\text { - Fabricantes - } \\
\text { Importadoras - } \\
\text { Distribuidoras - } \\
\text { Farmácias e Drogarias }\end{array}$ & $\begin{array}{c}\text { Revogada (pela } \\
\text { IN 01/11) }\end{array}$ \\
\hline 2011 & $\begin{array}{l}\text { Instrução Normativa 01, de } \\
\text { 02.03.11 }\end{array}$ & $\begin{array}{l}\text { Revoga a Instrução Normativa n. 11, } \\
\text { de } 29 \text { de outubro de } 2010 \text {. }\end{array}$ & $\begin{array}{l}\text { - Fabricantes - } \\
\text { Importadoras - } \\
\text { Distribuidoras - } \\
\text { Farmácias e Drogarias }\end{array}$ & Vigente \\
\hline 2011 & Portaria 225, de 02.03.11 & $\begin{array}{l}\text { Institui no âmbito da ANVISA Gru- } \\
\text { po de Trabalho para avaliação da } \\
\text { eficiência e da efetividade das al- } \\
\text { ternativas tecnológicas para o ras- } \\
\text { treamento da produção e do consu- } \\
\text { mo de medicamentos com vistas á } \\
\text { implantação de sistema de rastrea- } \\
\text { mento que se coadune com os ob- } \\
\text { jetivos das políticas públicas de } \\
\text { acesso a medicamentos. }\end{array}$ & & Vigente \\
\hline
\end{tabular}

Fonte: Quadro modificado de CRUZ, 2001.

Para análise do panorama de falsificação no Brasil nos últimos anos, foram consultados os lotes de medicamentos falsificados disponíveis no site da ANVISA (www.anvisa.gov.br), no período janeiro/2005 a junho/2009, complementados com a consulta no site da Imprensa Nacional (www.in.gov.br) no período de junho a dezembro de 2009 de forma a contemplar todas as publicações de apreensão e inutilização de medicamentos falsificados em 2009. Foram desconsiderados para fins da análise 2 lotes citados nas listas 
da ANVISA não enquadrados como falsificados de acordo com o conceito adotado pela OMS. A partir da compilação e análise destes dados, foi possível avaliar os produtos, classes terapêuticas e formas farmacêuticas mais falsificadas.

$\mathrm{Na}$ Tabela 1, são apresentados os medicamentos cujos lotes foram falsificados no período de 2005 a 2009; pode-se concluir que os produtos Cialis $(29 / 56)$ e Viagra (13/56) foram os medicamentos mais falsificados no período. Consequentemente, quando se analisa por classe terapêutica, os produtos para disfunção erétil (classe terapêutica vasodilatadores) representam $77 \%$ dos lotes falsificados (43/56), conforme apresentado na Tabela 2. Além disso, é importante destacar os produtos com ação anabolizante, Deca Durabolin (1/56), Durateston (5/56), Hemogenin (4/56) que juntos somam $18 \%$.

\section{Tabela 1 - Número de Lotes de Medicamentos Falsificados por Produto no Brasil - 2005-2009}

\begin{tabular}{|c|c|c|c|c|c|c|}
\hline Produto & 2005 & 2006 & 2007 & 2008 & 2009 & Total geral \\
\hline Cialis (tadalafila) & 1 & 5 & 4 & 6 & 13 & 29 \\
\hline Deca Durabolin (decanoato de nandrolona) & & & & 1 & & 1 \\
\hline $\begin{array}{l}\text { Dibetam (fosfato dissódico de betametasona, } \\
\text { dipropionato de betametasona) }\end{array}$ & & & 1 & & & 1 \\
\hline $\begin{array}{l}\text { Durateston (isocaproato de testosterona, } \\
\text { decanoato de testosterona, fempropionato de } \\
\text { testosterona, propionato de testosterona) }\end{array}$ & & & & 4 & 1 & 5 \\
\hline Fluarix (vírus contra a gripe) & & 1 & & & & 1 \\
\hline Glivec (mesilato de imatinibe) & & & 1 & & & 1 \\
\hline Hemogenin (oximetolona) & & & & & 4 & 4 \\
\hline Levitra (cloridrato de vardenafila) & & & 1 & & & 1 \\
\hline Viagra (citrato de sildenafila) & & 8 & 2 & 1 & 2 & 13 \\
\hline Total geral & 1 & 14 & 9 & 12 & 20 & 56 \\
\hline
\end{tabular}

Fonte: Lotes de medicamentos falsificados disponível no site da ANVISA $<$ www.anvisa.gov.br> e da Imprensa Nacional <www.in.gov.br>.

Quando se avalia por forma farmacêutica, a mais falsificada foi a de comprimidos (48/56), seguida de produtos injetáveis $(8 / 56)$, conforme Tabela 3. 


\section{Tabela 2 - Número de Lotes de Medicamentos Falsificados por Classe Terapêutica no Brasil - 2005-2009}

\begin{tabular}{lcccccc}
\hline Classe Terapêutica & 2005 & 2006 & $\mathbf{2 0 0 7}$ & $\mathbf{2 0 0 8}$ & $\mathbf{2 0 0 9}$ & Total geral \\
\hline Anabolizantes simples & & & & 1 & & 1 \\
Andrógenos - associações medicamentosas & & & & 4 & 1 & 5 \\
Antineoplásico & & 1 & & & 1 \\
Glicocorticóides & & 1 & & & 1 \\
$\begin{array}{l}\text { Outros Produtos que atuam no sangue e } \\
\text { hematopoiese }\end{array}$ & & & & 4 & 4 \\
Vacinas & 1 & 13 & 7 & 7 & 15 & 43 \\
Vasodilatadores & 1 & 14 & 9 & 12 & 20 & 56 \\
Total geral & & & & & & 1 \\
\hline
\end{tabular}

Fonte: Lotes de medicamentos falsificados disponível no site da ANVISA $<$ <ww.anvisa.gov.br> e na Imprensa Nacional <www.in.gov.br>.

\begin{tabular}{lcccccc|}
\hline Categoria & 2005 & $\mathbf{2 0 0 6}$ & $\mathbf{2 0 0 7}$ & $\mathbf{2 0 0 8}$ & $\mathbf{2 0 0 9}$ & Total geral \\
Comprimidos & 1 & 13 & 8 & 7 & 19 & 48 \\
Injetáveis & & 1 & 1 & 5 & 1 & 8 \\
\hline Total geral & 1 & 14 & 9 & 12 & 20 & 56 \\
\hline
\end{tabular}

Fonte: Lotes de medicamentos falsificados disponível no site da ANVISA $<$ www.anvisa.gov.br> e na Imprensa Nacional <www.in.gov.br>.

Segundo a ANVISA, em termos quantitativos, 130 toneladas de produtos irregulares foram apreendidas em $2008^{\left({ }^{31}\right)}$ e cerca de 300 , em 2009(32).

De acordo com o Dr. Dirceu Raposo, ex-diretor-presidente da ANVISA, os produtos falsificados são originários principalmente do Paraguai e Bolívia, não tendo sido encontrados até o momento fabricantes de produtos falsificados no Brasil ${ }^{(33)}$.

(31) Lei cria sistema nacional de controle de medicamentos. ANVISA Publica. 16 jan. 2009. Disponível em: <http://www.anvisa.gov.br/divulga/noticias/2009/160109.htm>. Acesso em: 20 jun. 2010.

(32) CURY, L. Campanha orienta população sobre riscos dos medicamentos falsificados. 12 abr. 2010. Disponível em: <http://portal.anvisa.gov.br/wps/portal/anvisa/busca/!ut/p/c5/04_SB8K8xLL M9MSSzPy8xBz9CP0os3jvQA9PdwMDI0v_EAsXA0-TkCAPS29nfzdDQ6B8pFm8s7ujh4m5j4GBgZ mTs4Gnu6mfmWmgv4GBvxEB3eEg-_DrB8kb4ACOBvp-Hvm5qfaR-IHmOO3xMNKPzEINT0yu1C IjTDI MgIVBABMM9TI/dl3/d3/LOIJSkIna2shLOICakFBTXIBQkVSQOIBISEvWUZOQzFOS18yN3chLzdfS1FIS UcwMDI5T1Q4RDBJNFRSSDILQ09GSDI!/?WCM_GLOBAL_CONTEXT=/wps/wcm/connect/Anvisa/ Anvisa/Inicio/Medicamentos/Publicacao+Medicamentos/Campanha+orienta+populacao+sobre+riscos +dos+medicamentos+falsificados>. Acesso em: 20 jun. 2010.

(33) APREENSÃO recorde de remédios serve de alerta para consumidores. 14 abr. 2009. Disponível em: <http://webcache.googleusercontent.com/search?q=cache:jeH_AUH3pfwJ:portal.mj.gov.br/data/ Pages/MJ61EDAA11ITEMID7B4CBDF650D34B5FB7F4D65A4506AB50PTBRNN.htm+Apreens\% $\mathrm{C} 3 \% \mathrm{~A} 30+$ recorde+de+rem $\% \mathrm{C} 3 \% \mathrm{~A} 9 \mathrm{dios}+$ serve+de+alerta+para+consumidores $\& \mathrm{~cd}=1 \& \mathrm{hl}=\mathrm{pt}$ BR\&ct=clnk\&gl=br>. Acesso em: 20 jun. 2010. 


\section{MERCADO FARMACÊUTICO E SISTEMA NACIONAL DE CONTROLE DE MEDICAMENTOS (LEI N. 11.903/09)}

O mercado farmacêutico do país é formado por 550 indústrias, cerca de 3.800 distribuidoras e mais de 79 mil farmácias e drogarias ${ }^{(34)}$. De acordo com dados de 2008, o Brasil representa $39 \%$ do mercado da América Latina e está em nono lugar do ranking do mercado farmacêutico mundial, além de ser um dos "mercados farmacêuticos emergentes" junto com a Rússia e Índia, atrás somente da China(35)(36).

Com objetivo de possibilitar o rastreamento dos medicamentos, foi criado em 2009 pela Lei n. 11.903 o Sistema Nacional de Controle de Medicamentos, envolvendo a produção, comercialização, dispensação e a prescrição médica, odontológica e veterinária( ${ }^{(37)}$. A implantação e a coordenação do sistema são de responsabilidade da ANVISA (Lei n. 11.903/ 09, Art. $\left.4^{\circ}\right)$.

O controle será realizado por meio de sistema de identificação exclusivo dos produtos, prestadores de serviços e usuários com o emprego da tecnologia de captura, armazenamento e transmissão dos dados. A tecnologia foi definida pela RDC n. 59/09 e trata-se do código bidimensional, chamado de Datamatrix, o qual permite o armazenamento de milhares de informações em um espaço relativamente pequeno( ${ }^{(38)(39)}$, como o número do registro, número do lote, data de fabricação, prazo de validade, reunidas no Identificador Único de Medicamento (IUM). As embalagens secundárias (caixa) de todos os medicamentos deverão obrigatoriamente conter o código, com exceção dos medicamentos que não possuem embalagem secundária, os quais deverão conter o mecanismo de rastreabilidade em sua embalagem primária.

(34) CONSELHO FEDERAL DE FARMÁCIA. Estabelecimentos Farmacêuticos no Brasil: Relatório da Comissão de Fiscalização emitido em dezembro de 2009, com base nos Relatórios de Atividades Fiscais dos Conselhos Regionais de Farmácia. Disponível em: <http://www.cff.org.br/ \#[ajax]pagina\&id=138>. Acesso em: 20 jun. 2010.

(35) IMS Brazil (Country Profile). Disponível em: <http://www.imshealth.com/portal/site/imshealth/ menuitem.a46c6d4df3db4b3d88f611019418c22a/?vgnextoid=819e58a2d5e85210VgnVCM100000ed1 52ca2RCRD\&cpsextcurrchannel=1>. Acesso em: 20 jun. 2010.

(36) IMS Announces 17 Countries Now Rank as High-Growth 'Pharmerging' Markets; Forecast to Contribute Nearly Half of Industry Growth by 2013. 16 mar. 2010. Disponível em: <http:// www.imshealth.com/portal/site/imshealth/menuitem.a46c6d4df3db4b3d88f611019418c22a/ ?vgnextoid=01624605b5367210VgnVCM100000ed152ca2RCRD\&vgnextchannel=41a67900b55a5110Vg nVCM10000071812ca2RCRD\&vgnextfmt=default>. Acesso em: 20 jun. 2010.

(37) Medida combate falsificação e roubo de cargas. Negócios públicos. Set. 2008. Disponível em: http://www.abso.org.br/novo/site/eventos/Materia_Geocidades.pdf Acesso em: 30 maio 2010.

(38) GSI Data Matrix. Disponível em: <http://www.gs1us.org/standards/barcodes/gs1_datamatrix> Acesso em: 22 jun. 2010.

(39) THE TURKISH "Pharmaceuticals Track \& Trace System (ITS)". Disponível em: <http:// www.iegm.gov.tr/Default.aspx?sayfa=tracking\&lang=en>. Acesso em 22 jun. 2010. 
A implantação do Sistema será realizada no prazo de 3 anos, de forma gradual, conforme prazos descritos no art. 5으 da Lei n. 11.903/09:

I - no primeiro ano, fabricantes e fornecedores (distribuidoras e comércios varejistas);

II - no segundo ano, compradores, produtos aviados ou dispensados e sua quantidade e unidades de transporte/logística;

III - no terceiro ano, consumidores/pacientes, prescrição (inclusive os produtos não aviados numa receita com múltiplos produtos) e profissional prescritor.

De acordo com a RDC n. 59/09, o código bidimensional contendo o IUM deverá ser impresso sob uma etiqueta de segurança, o qual permitirá ao consumidor verificar a autenticidade do medicamento por meio de leitores específicos disponibilizados gratuitamente a todas as farmácias e drogarias do país ${ }^{(40)(41)}$. De acordo com a ANVISA, o custo da etiqueta será de R\$ 0,07 sem incidência de impostos e o impacto médio nos preços de medicamentos de $0,05 \%$, já para produtos que custam até $R \$ 5,00$, que representam cerca de $20 \%$ do mercado brasileiro, o impacto será de $2,6 \% .^{(42)(43)}$ De acordo com as entidades do setor farmacêutico, a alta poderia variar de 6 a 23\% para produtos genéricos ${ }^{(44)}$.

Portanto, a partir da implantação do novo mecanismo de autenticidade (etiqueta) e rastreabilidade (código bidimensional), será possível verificar se o medicamento é verdadeiro, assim como visualizar todo o histórico do caminho percorrido desde a fabricação até a entrega ao consumidor, a partir do registro de todas as transações na cadeia.

De acordo com a ANVISA, apesar dos gastos com a própria etiqueta, não há grandes impactos na cadeia de produção, uma vez que o

(40) TECNOLOGIA para rastreabilidade de medicamentos está definida. 25 nov. 2009. Disponível em: <http://www.anvisa.gov.br/divulga/noticias/2009/251109_1.htm>. Acesso em: 20 dez. 2009.

(41) ANVISA Debate discute rastreabilidade de medicamentos. 08 dez. 2009. Disponível em: <http:// portal.anvisa.gov.br/wps/portal/anvisa/profsaude/lut/p/c4/04_SB8K8xLLM9MSSzPy8xBz9CP0o

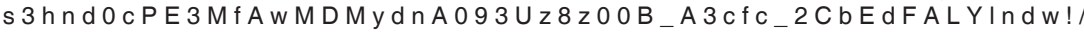
?WCM_PORTLET=PC_7_CGAH47L0006BCOIG5N65Q00ON1_WCM\&WCM_GLOBAL_CONTEXT=/wps/ $\mathrm{wcm} /$ connect/anvisa/anvisa/sala+de+imprensa/noticias/anvisa+debate+discute+rastreabilidade+de+ medicamentos>. Acesso em 20 dez. 2009.

(42) ANVISA lança selo de segurança para medicamentos. Disponível em: <http://portal.anvisa.gov.br/ wps/portal/anvisa/home/!ut/p/c5/04_SB8K8xLLM9MSSzPy8xBz9CP0os3hnd0cPE3MfAwMDMydn A093Uz8z00B_AwN_Q_1wkA48Kowg8gY4gKOBvp9Hfm6qfkF2dpqjo6liAJYj_8M!/dl3/d3/LOIDUOIKSW dra0EhIS9JTIJBQUlpQ2dBek15cUEhL1ICSIAxTkMxTktfMjd3ISEvN19DROFINDdMMDAwNkJDMEIHNU42NV FPMDg3NQ!!/?WCM_PORTLET=PC_7_CGAH47L0006BC0IG5N65QO0875_WCM\&WCM_GLOBAL_ CONTEXT=/wps/wcm/connect/anvisa/anvisa/sala+de+imprensa/noticias/anvisa+lanca+selo+de+ seguranca+para+medicamentos>. Acesso em 07 mar. 2011.

(43) PERGUNTAS e Respostas sobre Rastreabilidade. Disponível em: <http://www.anvisa.gov.br/ medicamentoverdadeiro/impressos/rastreabilidade.pdf>. Acesso em 07. Mar. 2011.

(44) ANVISA suspende implantação de selo de segurança em medicamentos. Disponível em: <http:/ /agenciabrasil.ebc.com.br/web/ebc-agencia-brasil/enviorss/-/journal_content/56/19523/3203415>. Acesso em 07 mar. 2011. 
levantamento realizado apontou que a implantação das etiquetas seria mais barata que a implantação do código bidimensional, por causa dos custos de impressoras e eventuais adaptações nas linhas produtivas. Além disso, segundo a ANVISA, verificou-se a existência de etiquetadoras em $57 \%$ das unidades fabricantes dos medicamentos ${ }^{(45)}$.

Assim como as indústrias, os distribuidores e comércios varejistas deverão arcar com o desenvolvimento, aquisição ou adaptação de programa ou sistema informatizado (RDC n. 59/09, art. 10). A Resolução também estabelece que todas as transações na cadeia devem ser registradas e disponíveis aos órgãos de fiscalização do Sistema (art. $2^{\circ}$ ), que os bancos de dados deverão relacionar o IUM, CNPJ das empresas (remetente e/ou receptora) e as transações realizadas (arts. 5으. 6으 e $7^{\circ}$ ) e que os sistemas informatizados deverão ser compatíveis de modo a garantir a interoperabilidade (art. 8). Após discussão entre a ANVISA e o Conselho Nacional de Política Fazendária (CONFAZ), foi definido que o Sistema de Nota Fiscal Eletrônica (NF-e) pode ser utilizado como meio de transmissão e armazenamento dos dados relativos ao IUM dos medicamentos o que permitiria a interoperabilidade entre os bancos de dados e também contribuir no combate à sonegação fiscal.

São resumidas no Quadro 2 as informações que devem constar nas embalagens secundárias de medicamentos de acordo com o sistema atual e o proposto pela Lei n. 11.903/09 e pela RDC n. 59/09. No sistema atual, os principais elementos de segurança são a tinta reativa e lacre ou selo ${ }^{(46)}$ e com o novo sistema passará a ser a etiqueta e o código bidimensional.

Quadro 2: Quadro comparativo das embalagens secundárias de medicamentos conforme sistema atual e pelo proposto pela Lei n. 11.903/09

\begin{tabular}{|ccc|}
\hline Categoria & Sistema atual & $\begin{array}{c}\text { Sistema proposto } \\
\text { (Lei 11.903/09) }\end{array}$ \\
\hline Nome comercial & $\begin{array}{c}\text { Obrigatório, exceto } \\
\text { genéricos }\end{array}$ & $\begin{array}{c}\text { Obrigatório, exceto } \\
\text { genéricos }\end{array}$ \\
\hline Denominação genérica & Obrigatório & Obrigatório \\
\hline Número do registro & Obrigatório & Obrigatório \\
\hline Data de fabricação & Obrigatório & Obrigatório \\
\hline Data de validade & Obrigatório & Obrigatório \\
\hline
\end{tabular}

(45) PERGUNTAS e Respostas sobre Rastreabilidade. Disponível em: <http://www.anvisa.gov.br/ medicamentoverdadeiro/impressos/rastreabilidade.pdf> Acesso em 07 mar. 2011.

(46) GUIA Prático para Identificação de Medicamentos Irregulares no Mercado. Brasília: Anvisa, 2010. p. 13. Disponível em: <http://www.anvisa.gov.br/medicamento_verdadeiro/impressos/Guia_Pratico_ Grafica.pdf>. Acesso em 20 jun. 2010. 


\begin{tabular}{|c|c|c|}
\hline Categoria & Sistema atual & $\begin{array}{c}\text { Sistema proposto } \\
\text { (Lei } 11.903 / 09)\end{array}$ \\
\hline Número do lote & Obrigatório & Obrigatório \\
\hline $\begin{array}{c}\text { Farmacêutico } \\
\text { Responsável e número } \\
\text { do Conselho Regional de } \\
\text { Farmácia (CRF) }\end{array}$ & Obrigatório & Obrigatório \\
\hline $\begin{array}{c}\text { Telefone do Serviço de } \\
\text { Atendimento ao } \\
\text { Consumidor (SAC) }\end{array}$ & Obrigatório & Obrigatório \\
\hline $\begin{array}{l}\text { Nome, endereço e CNPJ } \\
\text { do detentor do registro }\end{array}$ & Obrigatório & Obrigatório \\
\hline $\begin{array}{l}\text { Lacre ou selo de } \\
\text { segurança }\end{array}$ & Obrigatório & Obrigatório \\
\hline $\begin{array}{l}\text { Tinta reativa } \\
\text { ("raspadinha") }\end{array}$ & Obrigatório & Facultativo \\
\hline Código GTIN & Obrigatório & Facultativo \\
\hline Etiqueta de segurança & Não previsto & Obrigatório \\
\hline $\begin{array}{l}\text { Código bidimensional } \\
\text { (Datamatrix) }\end{array}$ & Não previsto & Obrigatório \\
\hline
\end{tabular}

A partir da implantação do mecanismo de identificação e autenticidade, será facultativa a inclusão na embalagem secundária, ou na sua ausência na embalagem primária, do código GTIN (código de barras), composto de 12 números mais 1 dígito verificador; os 3 primeiros dígitos indicam o código do país, os próximos 6 indicam o código da empresa e os 3 dígitos sequenciais (000 ao 999) indicam os itens comerciais.

Ambas as tecnologias (Datamatrix e código GTIN) são reguladas e administradas pela GS1, organização dedicada ao desenvolvimento e implementação de padrões globais para aumentar a eficiência e visibilidade da cadeia de suprimentos. O código bidimensional vem sendo utilizado com sucesso em vários países europeus como França e Turquia, sendo que no último seu uso é obrigatório( ${ }^{(47)}$. Além disso, esse código foi recentemente utilizado em um projeto piloto na Suécia com colaboração da EFPIA [Federação Europeia de Associações e Indústrias Farmacêuticas] de setembro de 2009 até janeiro de 2010, com resultados positivos, possibilitando a identificação efetiva de embalagens falsificadas, como também aquelas com prazo de validade expirado e produtos em fase de recolhimento ${ }^{(48)}$.

(47) 2D DATA Matrix Coding ensure pharmaceuticals remain forgery proof. Disponível em: <http:// www.aps-direct.com.au/PM_Datamatrix_Exp_en.pdf>. Acesso em: 20 jun. 2010.

(48) EUROPEAN FEDERATION OF PHARMACEUTICAL INDUSTRIES AND ASSOCIATIONS. Results demonstrate EFPIA anti-counterfeit product verification pilot project successful. 14 abr. 2010. Disponível em: <http://www.efpia.eu/Content/Default.asp?PagelD=559\&DoclD=8771>. Acesso em: 24 jun. 2010. 
Com a recente publicação da Instrução Normativa n. 01/11 pela ANVISA, foi revogada a Instrução Normativa n. 11/10 que definia os prazos para início da aplicação das etiquetas nas embalagens dos medicamentos. Essa medida foi tomada em resposta à Resolução CMED n. 02/11 expedida pelos ministros da Câmara de Regulação do Mercado de Medicamentos (CMED) que recomendaram à ANVISA reavaliar a eficiência e efetividade das alternativas tecnológicas para implantação do sistema. Para tanto, foi criado um Grupo de Trabalho, formado por representantes da ANVISA, dos Ministérios da Saúde, da Justiça e do Desenvolvimento, Indústria e Comércio Exterior, com um prazo de 60 dias para apresentar um parecer de maneira a subsidiar eventuais medidas para o estabelecimento dos mecanismos de implantação e coordenação do Sistema Nacional de Controle de Medicamentos. ${ }^{(49)}$

Para conhecer a opinião do Setor Regulado com relação à nova lei e o mecanismo escolhido pela ANVISA, foi enviado um questionário (Anexo A) às associações de indústrias farmacêuticas Sindusfarma (Sindicato da Indústria de Produtos Farmacêuticos no Estado de São Paulo), Interfarma (Associação da Indústria Farmacêutica de Pesquisa) e Alanac (Associação dos Laboratórios Farmacêuticos Nacionais). Das 3 entidades, apenas a Alanac não respondeu ao questionário enviado.

O Sindusfarma e a Interfarma concordam que os mecanismos existentes hoje podem ser facilmente copiados ou fraudados e, por este motivo, acreditam que a proposta de aperfeiçoamento proporcionará um maior controle, beneficiando o setor regulado, a agência reguladora e a sociedade.

Entretanto, estas defendem apenas a impressão do código bidimensional diretamente na embalagem sem o uso da etiqueta, uma vez que a inclusão do código associado ao banco de dados já seria possível para garantir a rastreabilidade e consequentemente a autenticidade de determinado medicamento; ademais, acreditam que a etiqueta, assim como os mecanismos atuais, poderiam ser alvos de falsificação pela máfia cada vez mais especializada e representariam maior custo na implantação do novo Sistema, além dos gastos com logística, segurança e controle de qualidade das mesmas. A Sindusfarma enfatiza que o uso da etiqueta seria limitado ao Brasil, enquanto o código permitiria a integração com outros países, via autoridades sanitárias e policiais.

(49) ANVISA aprofunda discussão sobre rastreabilidade de medicamentos. 03 mar. 2011. Disponível em: <http://websphere.anvisa.gov.br/wps/portal/anvisa/home/lut/p/c5/04_SB8K8xLLM9MSSzPy8 xBz9CP0os3hnd0cPE3MfAwMDMydnA093Uz8z00B_AwN_Q_1wkA48Kowg8gY4gKOBvp9Hfm6qfkF2 dpqjo6liAJYj_8M!/dl3/d3/LOIDUOIKSWdra0EhIS9JTIJBQUIpQ2dBek15cUEhL1ICSIAxTkMxTktfMjd3ISE vN19DR0FINDdMMDAwNkJDMEIHNU42NVFPMDg3NQ!!/?WCM_PORTLET=PC_7_CGAH47L0006B C0IG5N65Q00875_WCM\&WCM_GLOBAL_CONTEXT=/wps/wcm/connect/anvisa/anvisa/ sala+de+imprensa/noticias/anvisa+aprofunda+discussao+sobre+rastreabilidade+de+medicamentos>. 


\section{DISCUSSÃO}

A falsificação de medicamentos representa um grave problema de saúde pública, o que justifica um maior controle de toda cadeia farmacêutica desde a produção até a dispensação de medicamentos, principalmente pelo perfil peculiar do mercado brasileiro com grande número de distribuidoras e comércio varejistas. Os mecanismos atuais de segurança não se mostram suficientes, considerando a tendência de aumento no número de falsificações no mercado formal de medicamentos no Brasil.

A Lei n. 11.903/09 cria um novo sistema a partir do qual será possível rastrear desde a produção até o consumo de medicamentos por meio de tecnologia de captura, armazenamento e transmissão eletrônica de dados. A RDC n. 59/09, que regulamenta essa lei, determina que a tecnologia (código bidimensional) deverá ser impressa sob uma etiqueta de segurança para permitir o rastreamento e a identificação única de cada unidade de venda de medicamentos.

A grande vantagem deste sistema é a possibilidade de identificação de produtos falsificados no ato da compra, garantindo maior segurança aos usuários. Além disso, pode-se detectar outros produtos irregulares, como os oriundos de roubo de carga ou que estejam em fase de recolhimento por questões de segurança, beneficiando assim o consumidor final.

Por outro lado, o novo sistema irá aumentar os custos para todos os atores da cadeia, principalmente para a indústria farmacêutica, uma vez que deverão arcar com as despesas da implantação e manutenção dos mecanismos de identificação e segurança.

A ANVISA defende que os custos dos fabricantes irão reduzir principalmente com a logística e pela extinção dos mecanismos de segurança como a tinta reativa, o que não justificaria qualquer aumento do preço, entretanto, as entidades do setor farmacêutico acreditam que haverá aumento dos custos de logística e de custos industriais.

Com a publicação da Instrução Normativa n. 01/11 e Portaria n. 225/11, a ANVISA irá reavaliar o mecanismo escolhido de forma a não impactar no preço final do medicamento, o que iria consequentemente contra as políticas públicas de acesso a medicamentos existentes.

\section{CONSIDERAÇÕES FINAIS}

A partir da década de 1990, novas legislações surgiram no Brasil e afetaram diretamente ou indiretamente a falsificação de medicamentos. Entretanto, verificou-se no presente trabalho um aumento no número de lotes falsificados apreendidos nos últimos 5 anos no Brasil, seguindo assim 
a tendência mundial de crescimento conforme alerta emitido em abril último pela OMS. Essa constatação é extremamente relevante, uma vez que se trabalha com dados subestimados na questão de falsificação de medicamentos.

Apesar da maioria dos lotes falsificados no Brasil serem destinados à disfunção erétil ou com ação anabolizante e podem ser primariamente atribuídos ao mercado informal de compra e venda de medicamentos através de academias e internet, é preocupante a ocorrência de falsificação de medicamentos destinados a doenças graves como o antineoplásico e a vacina de vírus contra gripe, os quais podem representar um elevado risco à saúde da coletividade.

Em razão do risco sanitário, nenhuma falsificação de medicamentos é aceitável e, por este motivo, consideramos que a Lei n. 11.903/09 vem ao encontro do fortalecimento da legislação e do controle da cadeia, conforme recomendações da OMS.

Se por um lado a Lei per se pode trazer maior controle em todos os atores da cadeia, por outro, este também representa o primeiro desafio para implantação do novo sistema, considerando o número de atores envolvidos e a complexidade do novo sistema. Como exemplo, podemos citar a disponibilização de leitores específicos para a verificação da autenticidade das etiquetas a ser disponibilizados em todas as farmácias e drogarias do país.

A implantação do novo sistema acarretará aumento dos gastos em todos os envolvidos da cadeia farmacêutica, em especial, na indústria farmacêutica, no entanto, segundo a ANVISA, não haverá qualquer repasse no preço dos medicamentos para o consumidor final. Neste sentido, aqueles produtos com menor custo de produção correm o risco de terem sua produção descontinuada.

Após a implementação de todo o sistema, será possível recolher informações sobre a venda de medicamentos no Brasil, perfazendo uma importante ferramenta de saúde pública, possibilitando a realização de ações localizadas assim como melhor distribuição de medicamentos conforme o perfil de cada localidade.

A questão de falsificação exige medidas contínuas na prevenção e combate da mesma. Com base nisto, é relevante a publicação da Lei, a partir da qual será possível verificar a autenticidade e rastreabilidade dos medicamentos e, em teoria, reduzir efetivamente o número de casos de medicamentos falsificados. No entanto, tão importante quanto o aumento do controle da cadeia formal de medicamentos, outras medidas devem ser realizadas concomitantemente para combate do mercado ilegal, tais como a contínua fiscalização pelas autoridades sanitárias, o treinamento de fiscais e a conscientização da população sobre os riscos dos medicamentos 
falsificados. Outro empecilho são os prazos estabelecidos na Lei, considerando a complexidade e as implicações decorrentes da implementação da mesma.

Além disso, o uso da etiqueta irá aumentar o custo dos medicamentos pelos fabricantes e por ser um mecanismo previsto apenas no Brasil põe à prova sua necessidade. Por outro lado, o uso do código bidimensional com o Identificador Único de Medicamentos (IUM) pode se mostrar uma alternativa adequada neste momento, possibilitando a rastreabilidade de medicamentos na cadeia farmacêutica.

\section{REFERÊNCIAS BIBLIOGRÁFICAS}

2D DATA Matrix Coding ensure pharmaceuticals remain forgery proof. Disponível em: <http://www.aps-direct.com.au/PM_Datamatrix_Exp_en.pdf>. Acesso em: 20 jun. 2010.

ANVISA Debate discute rastreabilidade de medicamentos. 08 dez. 2009. Disponível em: <http://portal.anvisa.gov.br/wps/portal/anvisa/profsaude/!ut/p/ c4/04_SB8K8xLLM9MSSzPy8xBz9CP0os3hnd0cPE3MfAwMDMydnA093Uz 8z00B_A3cfc_2CbEdFALYIndw!/?WCM_PORTLET=PC_7_CGAH47L0006B C0IG5N65QO0ON1_WCM\&WCM_GLOBAL_CONTEXT=/wps/wcm/connect/ anvisa/anvisa/sala+de+imprensa/noticias/anvisa+debate+discute+ rastreabilidade+de+medicamentos>. Acesso em: 20 dez. 2009.

ANVISA e Ministério da Justiça no combate à pirataria. 4 dez. 2008. Disponível em: <http://portal.anvisa.gov.br/wps/portal/anvisa/busca/!ut/p/c5/04_SB8K8 x L L M 9 M S S z P y 8 x B z 9 C P O o s 3 j vQA 9 P d w M D I 0 __E A s X A 0 TkCAPS29nfzdDQ6B8pFm8s7ujh4m5j4GBgZmTs4Gnu6mfmWmgv4GBvxEB3eEg_DrB8kb4ACOBvp-Hvm5qfqR-IHmOO3xMNKPzEINT0yu1C_IjTDIMgIVBAB MM9TI/dl3/d3/LOIJSklna2shLOICakFBTXIBQkVSQOIBISEvWUZOQzFOS18y N3chLzdfS1FISUcwMDI5T1Q4RDBJNFRSSDILQ09GSDI!/?WCM_GLOBAL _CONTEXT=/wps/wcm/connect/Anvisa/Anvisa/Sala+de+Imprensa/Noticias/ Anvisa+e+Ministerio+da+Justica+no+combate+a+pirataria>. Acesso em: 20 jun. 2010.

APREENSÃO recorde de remédios serve de alerta para consumidores. 14 abr. 2009. Disponível em: < <http://webcache.googleusercontent.com/ search? q=cache:jeH_AUH3pfwJ:portal.mj.gov.br/data/Pages/ MJ61EDAA11ITEMID7B4CBDF650D34B5FB7F4D65A4506AB50PTBRN N.htm+Apreens\%C3\%A3o+recorde+de+rem\%C3\%A9dios+serve+de+alerta+ para+consumidores\&cd=1\&hl=pt-BR\&ct=clnk\&gl=br>. Acesso em: 20 jun. 2010.

BRASIL. Constituição (1988). Constituição da República Federativa do Brasil. Brasília, DF: Senado, 1988. Disponível em: <http://www.planalto.gov.br/ ccivil_03/constituicao/_ConstituiçaoCompilado.htm>. Acesso em: 26 jun. 2009. 
BRASIL. Lei n. 11.903, de 14 de janeiro de 2009. Dispõe sobre o rastreamento da produção e do consumo de medicamentos por meio de tecnologia de captura, armazenamento e transmissão eletrônica de dados. Diário Oficial da União, Brasília, DF, 15 jan. 2009. Disponível em: < http:// www.planalto.gov.br/ccivil_03/_Ato2007-2010/2009/Lei/L11903.htm>. Acesso em: 12 jun. 2010.

BRASIL. Lei n. 6.360, de 23 de setembro de 1976. Dispõe sobre a Vigilância Sanitária a que ficam sujeitos os Medicamentos, as Drogas, os Insumos Farmacêuticos e Correlatos, Cosméticos, Saneantes e Outros Produtos, e dá outras providências. Diário Oficial da União, Brasília, DF, 24 set. 1976. Disponível em: http://www.planalto.gov.br/ccivil_03/Leis/L6360.htm. Acesso em: 27 jun. 2010.

BRASIL. Lei n. 8.080, de 19 de setembro de 1990. Dispõe sobre as condições para a promoção, proteção e recuperação da saúde, a organização e o funcionamento dos serviços correspondentes e dá outras providências. Diário Oficial da União, Brasília, DF, 20 set. 1990. Disponível em: <http:// www.planalto.gov.br/ccivil_03/Leis/L8080.htm>. Acesso em: 12 jun. 2010.

BRASIL. Lei n. 9.782, de 26 de janeiro de 1999. Define o Sistema Nacional de Vigilância Sanitária, cria a Agência Nacional de Vigilância Sanitária, e dá outras providências. Diário Oficial da União, Brasília, DF, 27 jan. 1999. Disponível em: <http://www.planalto.gov.br/ccivil_03/Leis/L9782.htm>. Acesso em: 12 jun. 2010.

BRASIL. Projeto de Lei PL n. 6672/2002. Disponível em: <http:// www.camara.gov.br/internet/sileg/Prop_Detalhe.asp?id=50589>. Acesso em: 24 jun. 2010

BURNS, W. WHO launches taskforce to fight counterfeit drugs. Bulletin of the World Health Organization, v.84, n.9, p. 689-90, 2006. Disponível em: <http:// www.who.int/bulletin/volumes/84/9/news.pdf> Acesso em: 20 jun. 2010.

COMBATE à Pirataria. Parcerias. Anvisa. Disponível em: <http:// portal.mj.gov.br/data/Pages/MJF981C78FITEMID1FEF62A7A51144B8990 B9F29977F666APTBRIE.htm>. Acesso em: 20 jun. 2010.

CONSELHO FEDERAL DE FARMÁCIA. Estabelecimentos Farmacêuticos no Brasil: Relatório da Comissão de Fiscalização emitido em dezembro de 2009, com base nos Relatórios de Atividades Fiscais dos Conselhos Regionais de Farmácia. Disponível em: <http://www.cff.org.br/\#[ajax]pagina\&id=138>. Acesso em: 20 jun. 2010.

COURA, K. Dispara a venda ilegal na internet de remédios para emagrecer, ganhar músculos e até abortar. Oito em cada dez desses produtos são falsificados. E alguns deles não passam de farinha. Veja.com. 10 mar. 2010. Disponível em: <http://veja.abril.com.br/100310/perigo-com-p-124.shtml>. Acesso em: 13 jun. 2010. 
CRUZ, S. G. Falsificação de remédios e poder de polícia. Rio de Janeiro: América Jurídica, 2001. 305 p.

CURY, L. Campanha orienta população sobre riscos dos medicamentos falsificados. 12 abr. 2010. Disponível em: <http://portal.anvisa.gov.br/wps/ portal/anvisa/busca/!ut/p/c5/04_SB8K8xLLM9MSSzPy8xBz9CP0os3jvQA9 PdwMDIOv_EAsXA0-TkCAPS29nfzdDQ6B8pFm8s7ujh4m5j4GBgZmTs4Gnu 6mfmWmgv4GBvxEB3eEg-_DrB8kb4ACOBvp-Hvm5qfqR-IHmOO3xMNKPz EINTOyu1C_ljTDIMgIVBABMM9TI/dl3/d3/LOIJSkIna2shLOICakFBTXIBQkVS Q0IBISEvWUZOQzFOS18yN3chLzdfS1FISUcwMDI5T1Q4RDBJNFRSSDILQ09 GSDI!/?WCM_GLOBAL_CONTEXT=/wps/wcm/connect/Anvisa/Anvisa/Inicio/ Medicamentos/Publicacao+Medicamentos/Campanha+orienta+populacao+ sobre+riscos+dos+medicamentos+falsificados>. Acesso em: 20 jun. 2010.

E SE O MEDICAMENTO for falso? Disponível em: <http://portal.anvisa.gov.br/ wps/wcm/connect/ 66345900406 a afbf 9 b 5 efb 137 b $78 f 2 d c /$ terceira_falsificados1.pdf?MOD=AJPERES>. Acesso em: 19 jun. 2010.

EUROPEAN FEDERATION OF PHARMACEUTICAL INDUSTRIES AND ASSOCIATIONS. Results demonstrate EFPIA anti-counterfeit product verification pilot project successful. $14 \mathrm{abr}$. 2010. Disponível em: <http://www.efpia.eu/Content/ Default.asp?PagelD=559\&DoclD=8771>. Acesso em: 24 jun. 2010.

FÓRUM discute estratégias de combate à falsificação de medicamentos. Revista de Saúde Pública, São Paulo, v. 38, n. 5, p. 748-749, 2004. Disponível em: <http://www.scielo.br/pdf/rsp/v38n5/21770.pdf>. Acesso em: 26 jun. 2010.

GROWING threat from counterfeit medicines. Bulletin of the World Health Organization, v. 88, p. 247-248, 2010. Disponível em: <http://www.who.int/ bulletin/volumes/88/4/10-020410.pdf>. Acesso em: 20 jun. 2010.

GSI Data Matrix. Disponível em: <http://www.gs1us.org/standards/barcodes/ gs1_datamatrix>. Acesso em: 22 jun. 2010.

GUIA Prático para Identificação de Medicamentos Irregulares no Mercado. Brasília: Anvisa, 2010. 25 p. Disponível em: <http://www.anvisa.gov.br/ medicamento_verdadeiro/impressos/Guia_Pratico_Grafica.pdf $>$. Acesso em: 20 jun. 2010.

IMS Announces 17 Countries Now Rank as High-Growth 'Pharmerging' Markets; Forecast to Contribute Nearly Half of Industry Growth by 2013. 16 mar. 2010. Disponível em: <http://www.imshealth.com/portal/site/imshealth/ menuitem. a46c6d4df3db4b3d88f611019418c22a/?vgnextoid=01624605b $5367210 \mathrm{VgnVCM} 100000$ ed152ca2RCRD\&vgnextchannel=41a67900b55a5110 VgnVCM10000071812ca2RCRD\&vgnextfmt=default $>$. Acesso em: 20 jun. 2010.

IMS Brazil (Country Profile). Disponível em: <http://www.imshealth.com/portal/ site/imshealth/menuitem.a46c6d4df3db4b3d88f611019418c22a/ ?vgnextoid=819e58a2d5e85210VgnVCM100000ed152ca2RCRD\&cpsex tcurrchannel=1>. Acesso em: 20 jun. 2010. 
INSTITUTO BRASILEIRO DE ÉTICA CONCORRENCIAL. Sistema Eletrônico de Rastreamento e Autenticidade de Medicamentos. Etco. Disponível em: $<$ http://www.etco.org.br/user_file/etco-medicamentos-out2009.pdf>. Acesso em: 23 jun. 2010.

INTERNATIONAL FEDERATION OF PHARMACEUTICAL MANUFACTURERS \& ASSOCIATIONS. IFPMA launches Ten Principles on Counterfeit Medicines. 12 maio 2010. Disponível em: <http://www.ifpma.org/News/NewsReleaseDetail. aspx?nID=13800>. Acesso em: 26 jun. 2010.

INTERNATIONAL FEDERATION OF PHARMACEUTICAL MANUFACTURERS \& ASSOCIATION. The IFPMA Ten Principles on Counterfeit Medicines. 12 maio 2010. Disponível em: <http://www.ifpma.org/documents/NR13800/IFPMA Ten_Principles_on_Counterfeit_Medicines_12May2010.pdf>. Acesso em: 26 jun. 2010.

INTERNATIONAL MEDICAL PRODUCTS ANTI-COUNTERFEITING TASKFORCE (IMPACT) Terms of Reference. Disponível em <http:// www.who.int/impact/about/IMPACT_ToR.pdf>. Acesso em: 13 jun. 2010.

INTERNATIONAL MEDICAL PRODUCTS ANTI-COUNTERFEITING TASKFORCE. Frequently asked questions (IMPACT). Disponível em: <http://www.who.int/ impact/impact_q-a/en/index.html>. Acesso em: 13 jun. 2010.

LEI cria sistema nacional de controle de medicamentos. ANVISA Publica. 16 jan. 2009. Disponível em: <http://www.anvisa.gov.br/divulga/noticias/2009/ 160109.htm>. Acesso em: 20 jun. 2010.

MEDIDA combate falsificação e roubo de cargas. Negócios públicos. Set. 2008. Disponível em: <http://www.abso.org.br/novo/site/eventos/ Materia_Geocidades.pdf>. Acesso em: 30 maio 2010.

O REINCIDENTE. Revista Veja. 22 jul. 1998. Disponível em: <http:// veja.abril.com.br/220798/p_045a.html>. Acesso em: 19 jun. 2010.

SEADI, J. A. Crimes hediondos e a falsificação de medicamentos. Porto Alegre: EDIPUCRS, 2002. $118 \mathrm{p}$.

TECNOLOGIA para rastreabilidade de medicamentos está definida. 25 nov. 2009. Disponível em: <http://www.anvisa.gov.br/divulga/noticias/2009/ 251109_1.htm>. Acesso em: 20 dez. 2009.

THE TURKISH "Pharmaceuticals Track \& Trace System (ITS)". Disponível em: http://www.iegm.gov.tr/Default.aspx?sayfa=tracking\&lang=en. Acesso em: 22 jun. 2010.

WORLD HEALTH ORGANIZATION. Counterfeit Drugs Kill! Disponível em: <http:/ /www.who.int/impact/FinalBrochureWHA2008a.pdf>. Acesso em: 12 jun. 2010.

WORLD HEALTH ORGANIZATION. Frequently Asked Questions (Counterfeit medicine). Disponível em: <http://www.who.int/medicines/services/counterfeit/ faqs/en/index.html>. Acesso em: 18 jun. 2009. 
WORLD HEALTH ORGANIZATION. General information on counterfeit medicines. Disponível em: <http://www.who.int/medicines/services/counterfeit/ overview/en/>. Acesso em: 13 jun. 2010.

WORLD HEALTH ORGANIZATION. Guidelines for the development of measures to combact counterfeit drugs. Disponível em: <http://whqlibdoc.who.int/hq/1999/ WHO_EDM_QSM_99.1.pdf>. Acesso em: 26 jun. 2010.

WORLD HEALTH ORGANIZATION. Working Group for Prevention and Combat Drug Counterfeiting. Disponível em: <http://new.paho.org/hq/index.php?option= com_content\&task=view\&id=1583\&ltemid=513\&lang=en>. Acesso em: 26 jun. 2010.

\section{ANEXO A \\ Questionário enviado às associações de indústrias farmacêuticas (Sindusfarma, Alanac e Interfarma)}

A entidade acredita que os mecanismos de verificação da autenticidade de medicamentos que existem hoje são suficientes ou era mesmo necessário um aperfeiçoamento?

Há uma estimativa de quanto representa hoje o gasto com segurança no custo final do medicamento para as indústrias farmacêuticas?

A entidade considera adequada e suficiente a nova legislação de rastreabilidade dos medicamentos? E o mecanismo escolhido (etiqueta + código bidimensional), é o mais adequado?

A produção do medicamento vai ficar mais cara com a implementação do novo mecanismo da Anvisa (etiqueta e código bidimensional)? Quais os impactos para as indústrias farmacêuticas?

A Anvisa avalia que os laboratórios vão ter uma redução nos custos com a logística, a entidade concorda? 